\title{
Distinct impacts of air and root-zone temperatures on leaf and root features of cucumber seedlings: resource acquisition capacity, organ size and carbon-nitrogen balance
}

1 Xiaozhuo Wang ${ }^{1}$, Lihong Gao ${ }^{1 *}$, Yongqiang Tian ${ }^{*}$

${ }^{1}$ Beijing Key Laboratory of Growth and Developmental Regulation for Protected Vegetable Crops, College of Horticulture, China Agricultural University, Yuanmingyuan West Road No.2, Haidian District, Beijing 100193, China

\section{* Correspondence:}

Lihong Gao: gaolh@ cau.edu.cn

Yongqiang Tian: tianyq1984@cau.edu.cn

Short Title: Air and root-zone temperatures influence carbon-nitrogen balance

Estimated length of the Manuscript: 5600 words

Figures 1-7, Tables 1-4, Supplementary Figures S1, Supplementary Table S1-S3

The author responsible for distribution of materials integral to the findings presented in this article in accordance with the policy described in the Instructions for Authors is: Lihong Gao

(gaolh@cau.edu.cn) and Yongqiang Tian (tianyq1984@cau.edu.cn)

Keywords: root-zone temperature, air temperature, carbon-nitrogen balance, biomass allocation, cucumber seedling, plant phenotypic plasticity, plant growth analysis.

\section{ABSTRACT}

Both low air $\left(T_{\text {air }}\right)$ and root-zone $\left(T_{\text {root }}\right)$ temperatures can inhibit resource (e.g. carbon and nutrients) acquisition by leaves and roots through various aspects, such as morphology, biomass allocation and assimilation/absorption capacity. However, it is still ambiguous whether $T_{\text {air }}$ and $T_{\text {root }}$ influence carbon $(\mathrm{C})$ and nutrient acquisition via the same approach. To this end, in this study, cucumber (Cucumis sativus $\mathrm{L}$.) seedlings were hydroponically grown under treatments arranged in complete factorial combination of two levels of $T_{\text {air }}\left(26 / 18^{\circ} \mathrm{C}\right.$ and $20 / 12^{\circ} \mathrm{C}$, day/night) and two levels of $T_{\text {root }}$ $\left(19^{\circ} \mathrm{C}\right.$ and $13^{\circ} \mathrm{C}$, constant). In general, both $T_{\text {air }}$ and $T_{\text {root }}$ affected leaf and root sizes mainly by regulating their morphology rather than biomass investment. Under low $T_{\text {air }}$ conditions $\left(20 / 18^{\circ} \mathrm{C}\right)$, elevated $T_{\text {root }}$ (compare $19^{\circ} \mathrm{C}$ versus $13^{\circ} \mathrm{C}$ ) did not influence $\mathrm{C}$ acquisition, but increased nitrogen $(\mathrm{N})$ acquisition mainly due to an increase in relative root length, resulting in decreased $\mathrm{C}: \mathrm{N}$ acquisition ratio. However, under low $T_{\text {root }}$ conditions $\left(13^{\circ} \mathrm{C}\right.$ ), elevated $T_{\text {air }}$ (compare $26 / 18^{\circ} \mathrm{C}$ versus $20 / 12^{\circ} \mathrm{C}$ ) enhanced both $\mathrm{C}$ and $\mathrm{N}$ acquisition mainly because of an increase of both $\mathrm{C}$ assimilation in leaves and $\mathrm{N}$ absorption by roots, resulting in relatively constant $\mathrm{C}: \mathrm{N}$ acquisition ratio. In addition, the $T_{\text {air }}$ and $T_{\text {root }}$ interaction was mainly observed in relative growth rate and root growth-related variables. Our results infer that $T_{\text {air }}$ and $T_{\text {root }}$ have distinct impacts on resource acquisition and carbon-nitrogen balance in plants. 


\section{INTRODUCTION}

39

40

41

42

43

44

Low temperature stress is a commonly encountered problem for plants in most temperate or highaltitude regions during cool-season cultivation. Low temperature may inhibit plant growth in a complex manner. Primarily, it limits the size of leaves and roots per unit plant biomass (leaf area ratio, LAR, and root length ratio, RLR) as an integrated result of altered biomass fraction (leaf mass fraction, $\mathrm{LMF}$, and root mass fraction, RMF) and morphological characteristics (leaf area per unit leaf mass, i.e. specific leaf area, SLA, and root length per unit root mass, i.e. specific root length, SRL) (Tachibana, 1982; Weih and Karlsson, 2001). In addition, it decreases the capacity of resource acquisition per unit size of leaves and roots (Clarkson et al., 1986; Delucia et al., 1992). These two aspects together inhibit the access to resources, and thus retard the relative growth rate (RGR) of plants (Loveys et al., 2002).

Knowledge about the relative contributions of various plant components to RGR may help us better predict plant responses to environmental variation and then pursue the right temperature control strategy. Previous researches (Loveys et al., 2002; Poorter et al., 2012) suggest that, for the aboveground part of plants, SLA usually plays a more flexible and important role than LMF in determining LAR, while net assimilation rate (NAR, increase in plant mass per unit leaf area and time) is more important than SLA in determining RGR at cool temperatures. However, such an analysis has not yet been carried out for the below-ground part of plants. Therefore, it is still unclear what the relative contributions are of SRL and RMF to the root length, and whether root absorption activity and root length contribute differently to nutrient acquisition, when plants face low temperature stress. A recent report by Freschet et al. (2015b) suggests that the size ratio of roots to leaves increases as nutrient limitation aggravates, and that RMF contributes more to RLR variation than SRL. It seems that RMF is more important than SRL in determining the root length at cool temperatures, because nutrient limitation can also be aggravated by reducing root-zone temperature. However, despite increased size ratio of roots to leaves, the relative size of roots is generally decreased at cool temperatures (Larigauderie et al., 1991), inferring that RMF and SRL may contribute in different ways to RLR.

Although many studies take temperature as a homogeneous whole, the spatial heterogeneity of temperature (e.g. air and root-zone temperatures) extensively exists either in natural environments (Deanedrummond and Glass, 1983; Walter et al., 2009) or under cultivation conditions (Gosselin and Trudel, 1985; Teitel et al., 1999; Kawasaki et al., 2014). It is well-known that air temperature $\left(T_{\text {air }}\right)$ is crucial for plant growth. Over the past decades, an increasing number of studies have shed light on the important role played by root-zone temperature $\left(T_{\text {root }}\right)$ in plant growth (Tachibana, 1987; Ahn et al., 1999; Murai-Hatano et al., 2008; Nagel et al., 2009; Poire et al., 2010). However, very few studies have attempted to compare the difference between $T_{\text {air }}$ and $T_{\text {root }}$ by independently and separately changing each type of temperature in one experiment. Therefore, it is still unclear how $T_{\text {air }}$ and $T_{\text {root }}$ separately affect the relative contributions of various plant components to RGR. Weih and Karlsson (2001) have pointed out that $T_{\text {air }}$ and $T_{\text {root }}$ have interactive effects on RGR, N productivity (the rate at which dry matter is produced per unit of $\mathrm{N}$ in plant biomass per unit of time) and leaf-N content. It means that plant response to root-zone cooling at optimal $T_{\text {air }}$ can not be simply predicted as a reverse of response to root-zone warming at low $T_{\text {air. }}$. Thus, it is needed to apply a complete factorial design to distinguish the different roles of $T_{\text {air }}$ and $T_{\text {root }}$ in plant growth.

Low temperature can limit resource (e.g. C and nutrients) acquisition by plants. Either $T_{\text {air }}$ or $T_{\text {root }}$ limitation alone may lead to unequal accessibilities of above- and below-ground parts to resources. Nevertheless, to maximize growth with minimum resource costs, plants generally tend to balance above- and below-ground resource acquisition capacities to achieve the status of $\mathrm{C}$-nutrient 
colimitation (Ryser and Eek, 2000; Maire et al., 2013). This mechanism is known as the 'balanced growth', 'optimal partitioning' or 'functional equilibrium' hypothesis (Brouwer, 1963; Davidson, 1969; Shipley and Meziane, 2002), which can be formalized as follows:

\section{$\mathrm{NAR} \times \mathrm{LMF} \times \mathrm{SLA} \propto \mathrm{SAR} \times \mathrm{RMF} \times \mathrm{SRL}$}

where NAR is plant $C$ net assimilation rate (per unit time and leaf area), and SAR is plant specific nutrient absorption rate (per unit time and root length) (Freschet et al., 2015a). This equation can be further transformed into:

$$
\begin{gathered}
\frac{N A R}{S A R} \propto \frac{R M F}{L M F} \times \frac{\text { SRL }}{\text { SLA }} \\
\frac{\text { NAR }}{\text { SAR }} \propto \frac{\text { RLR }}{\text { LAR }}
\end{gathered}
$$

89 Carbon-nutrient balance may be achieved through various strategies such as maintaining relatively smaller root size but higher SAR, or maintaining relatively constant size/activity ratio of leaves to roots through proportionately increasing NAR and SAR. For instance, in the study of Engels et al. (1992), nutrient uptake by roots is stimulated by increased temperature of maize shoot base (apical shoot meristem and zone of leaf extension) via raising shoot growth, even under low $T_{\text {root }}$ condition. Getting to know what kind of strategies plants choose can help us better understand the mechanisms of integrated plant responses to temperature limitation.

In this study, we conducted a complete factorial experiment, with two levels of $T_{\text {air }}$ (high and low) and two levels of $T_{\text {root }}$ (high and low), to investigate the independent and interactive effects of $T_{\text {air }}$ and $T_{\text {root }}$ on leaf and root growth, and carbon and nutrient assimilation in cucumber (Cucumis sativus L.) seedlings. The objectives were to examine (1) how $T_{\text {air }}$ and $T_{\text {root }}$ affect relative contributions of various plant components to plant growth and resource acquisition, and (2) whether $T_{\text {air }}$ has different effects on plant carbon-nutrient balance compared to $T_{\text {root }}$. Cucumber was chosen as a model plant because its growing point locates above the ground surface, which favors separate control of $T_{\text {air }}$ and $T_{\text {root }}$, and because it is a major greenhouse crop that is sensitive to low temperature (Terashima et al., 1998) and often grows under different $T_{\text {air }}$ and $T_{\text {root }}$ conditions due to artificial control (Gosselin and Trudel, 1985; Teitel et al., 1999; Urrestarazu et al., 2008).

\section{MATERIAL AND METHODS}

\section{Plant Material and Growth Conditions}

108 Cucumber (Cucumis sativus L. cv. Zhongnong No.16) seedlings were hydroponically cultured 109 according to the procedure described by Wang et al. (2016). Briefly, cucumber seeds were 110 pregerminated at $28^{\circ} \mathrm{C}$ for $26 \mathrm{~h}$, sown onto hydroponic devices and then cultured at $28^{\circ} \mathrm{C}$ for $30 \mathrm{~h}$ 111 under darkness. Germinated seedlings were maintained in hydroponic devices and cultured at $11226 / 18^{\circ} \mathrm{C}$ (day $10 \mathrm{~h} /$ night $14 \mathrm{~h}$ ) for 10 days, with 60-80\% relative humidity (RH) and approximately $113100 \mu \mathrm{mol}$ photons $\mathrm{m}^{-2} \cdot \mathrm{s}^{-1}$ during the day. Then, seedlings were transplanted onto brown glass bottles 114 placed and cultured at $26 / 18^{\circ} \mathrm{C}$ (day $10 \mathrm{~h} /$ night $14 \mathrm{~h}$ ) for another 5 days, with $60-80 \% \mathrm{RH}$ and 250 $115 \mu \mathrm{mol}$ photons $\mathrm{m}^{-2} \cdot \mathrm{s}^{-1}$ during the day. Full-strength Yamazaki nutrient solution (Yamazaki, 1982) at pH 6.0 was used for hydroponics throughout this experiment, and was refreshed every 5 days. The seedlings ready for treatment each had two intact cotyledons, one fully unfolded true leaf and one 118 new leaf beginning to unfold.

\section{Temperature Treatments}


On day 16 after germination, the cucumber seedlings were transferred into temperature controlling devices as described by Wang et al. (2016), which can respectively set and maintain temperature regimes around the shoots and roots. There were two regimes of both $T_{\text {air }}$ and $T_{\text {root }}$ in this experiment: $26 / 18^{\circ} \mathrm{C}$ (day/night, "high") and $20 / 12^{\circ} \mathrm{C}$ (day/night, "low") for $T_{\text {air }}$, and $19 \pm 1^{\circ} \mathrm{C}$ (all-day, "high") and $13 \pm 1{ }^{\circ} \mathrm{C}$ (constant, "low") for $T_{\text {root }}$ A $2 \times 2$ factorial design was employed to create treatments that included low $T_{\text {air }} /$ low $T_{\text {root }}(\mathrm{L} / \mathrm{L})$, low $T_{\text {air }} /$ high $T_{\text {root }}(\mathrm{L} / \mathrm{H})$, high $T_{\text {air }} /$ low $T_{\text {root }}(\mathrm{H} / \mathrm{L})$ and high $T_{\text {air }} /$ high $T_{\text {root }}(\mathrm{H} / \mathrm{H})$. To assure the comparability of the morphology and biomass allocation of seedlings among different treatments, each treatment lasted until the same stage of seeding development (i.e., for each seedling the second true leaf fully unfolded and the third true leaf was just about to unfold). The actual treatment periods were 10 days for low $T_{\text {air }}$ treatments $(\mathrm{L} / \mathrm{L}$ and $\mathrm{L} / \mathrm{H})$ and 5 days for high $T_{\text {air }}$ treatments $(\mathrm{H} / \mathrm{L}$ and $\mathrm{H} / \mathrm{H})$, respectively. Forty seedlings per treatment were cultivated.

\section{Growth Characteristics}

133 At both the beginning and ending of the treatments, seedlings were harvested to determine growth characteristics (seven replicates, three seedlings each replicate). Fresh leaves and roots were scanned (EPL/HN EXPREL/LION 4990, Japan), and the scanned images were used to quantify leaf area and total root length with WinRHIZO software (LC4800-II LA2400; Sainte-Foy, Canada). Additionally, the path length of each first-order lateral root (LR) on the basal half of main root, and the number of second-order LRs on each first-order LR were quantified with ImageJ software (V1.50b; Abràmoff et al., 2004). The definition of first- and second-order LR was the same as described by Kellermeier et al. (2014). After scanning, fresh plant tissues were separately (root, stem, cotyledon, the first true leaf and the second true leaf) oven-dried at $105^{\circ} \mathrm{C}$ for $15 \mathrm{~min}$ and at $85^{\circ} \mathrm{C}$ for $48 \mathrm{~h}$, and weighted for the dry mass. Total plant dry mass was calculated as the sum of all plant tissues. For calculating RGR, plants before and after treatment were paired based on the order of total plant dry weight, and then RGR was calculated for paired plants as described by Hunt (1978):

$$
\mathrm{RGR}=\frac{\ln W_{2}-\ln W_{1}}{T_{2}-T_{1}}
$$

where $W_{1}$ and $W_{2}$ are the total plant dry mass before and after treatment, respectively, and $T_{2}-T_{1}$ is the treatment period. SLA $\left(\mathrm{cm}^{2} \cdot \mathrm{g}^{-1}\right)$ and SRL $\left(\mathrm{m} \cdot \mathrm{g}^{-1}\right)$ were calculated as the leaf area per leaf dry mass and the root length per root dry mass, respectively. LMF $\left(\mathrm{g} \cdot \mathrm{g}^{-1}\right)$ and RMF $\left(\mathrm{g} \cdot \mathrm{g}^{-1}\right)$ were estimated as proportions of leaf dry mass and root dry mass of the total plant dry mass, respectively. LAR $\left(\mathrm{cm}^{2} \cdot \mathrm{g}^{-1}\right)$ and RLR $\left(\mathrm{m} \cdot \mathrm{g}^{-1}\right)$ were calculated as the leaf area and root length per total plant dry mass, respectively.

\section{Element Content and Absorption Rates}

After being weighted, the dry tissues of seedlings were ground into fine powder with a mortar and pestle for analysis of element contents. The contents of $\mathrm{C}$ and $\mathrm{N}$ in seedling tissues were determined by combusting the powder at $900^{\circ} \mathrm{C}$ within an elemental analyzer (vario PYRO cube, Germany). The contents of $\mathrm{P}, \mathrm{K}, \mathrm{Ca}, \mathrm{Mg}, \mathrm{Fe}, \mathrm{Mn}, \mathrm{Zn}$, and $\mathrm{Cu}$ were determined by digesting the powder with nitric acid in a microwave digestion system (MARS 240/50, CEM, USA) and then analyzing with an inductively coupled plasma atomic emission spectrometer (ICP-AES, ICP6300, Britain).

157 For nutrient elements, the whole plant absorption rate $\left(R_{x}, m g\right.$ element $\cdot g^{-1}$ plant biomass $\cdot \mathrm{d}^{-1}$, where $\mathrm{x}$ 158 can be $\mathrm{N}, \mathrm{P}, \mathrm{K}, \mathrm{Ca}, \mathrm{Mg}, \mathrm{Fe}, \mathrm{Mn}, \mathrm{Zn}$ or $\mathrm{Cu}$ ) and specific absorption rate on a root-length basis $\left(\mathrm{SAR}_{\mathrm{x}}\right.$, to Welbank (1962) as follows: 


$$
\mathrm{R}_{\mathrm{x}}=\frac{M_{2}-M_{1}}{T_{2}-T_{1}} \cdot \frac{\ln W_{2}-\ln W_{1}}{W_{2}-W_{1}}
$$

161 where $M_{1}$ and $M_{2}$ are the total content of element before and after treatments, respectively, and $R_{\mathrm{L} 1}$ and $R_{\mathrm{L} 2}$ are the total root length before and after treatments, respectively. The estimation of mean $\operatorname{RLR}(\overline{\mathrm{RLR}})$ over the treatment period was calculated as dividing $\mathrm{R}_{\mathrm{x}}$ by $\mathrm{SAR}_{\mathrm{x}}$.

To compare with $\mathrm{N}$ and other elements, the influx of $\mathrm{C}$ was also estimated in similar methods, the whole plant net assimilation rates of carbon $\left(\mathrm{R}_{\mathrm{C}}, \mathrm{mg} \mathrm{C} \cdot \mathrm{g}^{-1}\right.$ plant biomass $\left.\cdot \mathrm{d}^{-1}\right)$ and unit leaf rate of carbon $\left(\mathrm{NAR}_{\mathrm{C}}, \mathrm{mg} \mathrm{C} \cdot \mathrm{cm}^{-2}\right.$ leaf area $\left.\cdot \mathrm{d}^{-1}\right)$ were calculated as follows:

$$
\mathrm{R}_{\mathrm{C}}=\frac{M_{2}-M_{1}}{T_{2}-T_{1}} \cdot \frac{\ln W_{2}-\ln W_{1}}{W_{2}-W_{1}}
$$

where $L_{\mathrm{A} 1}$ and $L_{\mathrm{A} 2}$ are the total leaf area before and after treatments, respectively. Similarly, the estimation of mean LAR ( $\overline{\mathrm{LAR}})$ over the treatment period was calculated as dividing $\mathrm{R}_{\mathrm{C}}$ by $\mathrm{NAR}_{\mathrm{C}}$.

\section{Net Assimilation Rate of True Leaves}

Gas-exchange was measured on both true leaves with the LI-6400xt gas exchange analyzer (Li-Cor 6400xt, Lincoln, NE, USA) (four seedlings per treatment). Determination started from the third hour of a light period in the last day of treatment. The block temperature was set at the air temperature of the corresponding treatment, and the PAR and air relative humidity were maintained at $1200 \mu \mathrm{mol} \cdot \mathrm{m}$ ${ }^{2} \cdot \mathrm{s}^{-1}$ and $60-70 \%$, respectively. Net assimilation rate under $400 \mu \mathrm{mol} \mathrm{CO}_{2} \cdot \mathrm{mol}^{-1}$ reference $\mathrm{CO}_{2}$ concentration $\left(A_{400}\right)$ was recorded.

\section{Data Analysis}

Following the variance partitioning method described by Rees et al. (2010) and Freschet et al. (2015b), we calculated the relative contributions of variance in LMF and SLA to variance in LAR, of RMF and SRL to RLR, of NAR ${ }_{C}$ and $\overline{L A R}$ to $R_{C}$, and of $S A R_{N}$ and $\overline{R L R}$ to $R_{N}$. To avoid meaningless results, the variance partitioning was not performed if less than $15 \%$ variation was observed in LAR, $\mathrm{RLR}, \mathrm{R}_{\mathrm{C}}$ or $\mathrm{R}_{\mathrm{N}}$. Instead of relative contributions, direct effects of $\mathrm{R}_{\mathrm{C}}$ and $\mathrm{R}_{\mathrm{N}}$ on $\mathrm{RGR}$ were worked out using path coefficient analysis (Dewey and Lu, 1959).

The data and the graphs were processed using Microsoft Excel 2016 and Microsoft R Open 3.4.1. For multiple comparisons, data were $\log _{2}$ transformed and then subjected to one-way analysis of variance (ANOVA). When ANOVA indicated significant differences $(P<0.05)$, means were compared using Tukey HSD tests (software: IBM SPL/L Statistics 20, IBM Corporation, USA). Two-way ANOVA was performed to compare sources of variation, including $T_{\text {air }}, T_{\text {root }}$, and the $T_{\text {air }} \times T_{\text {root }}$ interaction.

\section{RESULTS}

\section{Plant Growth Parameters under Different Temperature Conditions}

190 Seedlings spent less time growing one new leaf under high $T_{\text {air }}$ conditions $(\mathrm{H} / \mathrm{L}$ and $\mathrm{H} / \mathrm{H})$ than under low $T_{\text {air }}$ conditions (L/L and $\left.\mathrm{L} / \mathrm{H}\right)$. Thus, although elevated $T_{\text {air }}$ decreased the total dry mass of seedlings at the end of the experiment, it significantly accelerated their RGR (H/L vs L/L, H/H vs $\mathrm{L} / \mathrm{H}$; Table 1). Elevated $T_{\text {root }}$ increased total dry mass and RGR at both levels of $T_{\text {air }}(\mathrm{L} / \mathrm{H}$ vs $\mathrm{L} / \mathrm{L}$, $\mathrm{H} / \mathrm{H}$ vs H/L). Significant interactive effects of $T_{\text {air }}$ and $T_{\text {root }}$ were observed on both total dry mass and RGR. Elevated $T_{\text {air }}$ significantly decreased leaf area at low $T_{\text {root }}(\mathrm{H} / \mathrm{L}$ vs $\mathrm{L} / \mathrm{L})$ and total root length at both levels of $T_{\text {root }}\left(\mathrm{H} / \mathrm{L}\right.$ vs L/L, H/H vs L/H). By contrast, elevated $T_{\text {root }}$ significantly increased total leaf area and total root length at both levels of $T_{\text {air }}(\mathrm{L} / \mathrm{H}$ vs $\mathrm{L} / \mathrm{L}, \mathrm{H} / \mathrm{H}$ vs H/L). Table 1 and 
Supplementary Figure S1 also display more details about how temperature treatments affected the size of leaves and roots. Compared with older tissues, the 2 nd true leaf and the 2 nd order LR, which newly developed during treatment, had higher size variation between treatments. Apparently, low $T_{\text {air }}$ combined with low $T_{\text {root }}$ resulted in a generally small and slowly-developed $\mathrm{L} / \mathrm{L}$ seedling. On this basis, elevated $T_{\text {air }}$ led to a fast-developed but still small seedling $(\mathrm{H} / \mathrm{L}$ vs $\mathrm{L} / \mathrm{L})$, elevated $T_{\text {root }}$ led to a large but still slowly-developed seedling ( $\mathrm{L} / \mathrm{H}$ vs $\mathrm{L} / \mathrm{L})$, and co-elevated $T_{\text {air }}$ and $T_{\text {root }}$ led to a large and fast-developed seedling (H/H vs L/L).

\section{Effects of $T_{\text {air }}$ and $T_{\text {root }}$ on the Components of Leaf and Root Size}

Elevated $T_{\text {air }}$ significantly raised LAR at each $T_{\text {root }}$ (Figure 1) and RLR at low $T_{\text {root }}(\mathrm{H} / \mathrm{L}$ vs L/L), but decreased RLR at high $T_{\text {root }}(\mathrm{H} / \mathrm{H}$ vs $\mathrm{L} / \mathrm{H})$. Elevated $T_{\text {root }}$ raised both LAR and RLR at each $T_{\text {air }}$, and the promoting effect on RLR was obviously stronger at low $T_{\text {air }}$ than at high $T_{\text {air }}$. Responses of SLA and SRL to temperature variation were similar to those of LAR and RLR, except for that SRL was not significantly affected by elevated $T_{\text {air }}$ at high $T_{\text {root }}(\mathrm{H} / \mathrm{H}$ vs $\mathrm{L} / \mathrm{H})$. As to biomass allocation, elevated $T_{\text {air }}$ increased LMF and decreased RMF (H/L vs L/L), while elevated $T_{\text {root }}$ showed reverse trends ( $\mathrm{L} / \mathrm{H}$ vs $\mathrm{L} / \mathrm{L})$, leading to unchanged $\mathrm{LMF}$ and increased $\mathrm{RMF}$ at co-elevated $T_{\text {air }}$ and $T_{\text {root }}(\mathrm{H} / \mathrm{H}$ vs $\mathrm{L} / \mathrm{L}$ ). For different leaves of a seedling, their biomass fractions may respond differently to temperature changes, depending on the leaf order (Figure 2). Elevated $T_{\text {air }}$ significantly increased the allocation ratio of biomass increment of the 2 nd true leaf, while elevated $T_{\text {root }}$ significantly decreased the allocation ratio of biomass increment of cotyledon. For the 1 st true leaf, temperature variation had no obvious influence on biomass allocation.

218 Changes in morphological characteristics (SLA and SRL) generally weighted more than biomass allocation (LMF and RMF) on determining responses of LAR and RLR to temperature variation (Figure 3). In the above ground parts, changes in SLA always contributed the major part of the variation in LAR no matter how temperature was changed. The relative contribution of SLA even exceeded 1 since LMF contributed negatively to the total variation in LAR. In the below ground parts, changes in SRL contributed more than RMF to the variation in RLR when $T_{\text {all }}\left(T_{\text {air }}+T_{\text {root }}\right)$ or $T_{\text {root }}$ was altered. Specially, only when $T_{\text {air }}$ changed at high $T_{\text {root }}(\mathrm{L} / \mathrm{H}$ vs $\mathrm{H} / \mathrm{H})$, the relative contribution of RMF became predominant.

The ratio of total leaf area to total root length (equivalent to LAR : RLR) varied a lot among different temperature treatments (Table 2). Considering the LAR : RLR of $\mathrm{H} / \mathrm{H}$ seedlings as a balanced standard, $T_{\text {air }}$ limitation led to a structure with relatively smaller leaves but larger roots in $\mathrm{L} / \mathrm{H}$ seedlings, while $T_{\text {root }}$ limitation did the opposite thing on H/L seedlings. Instead of proportionately inhibiting both leaf and root sizes, $T_{\text {all }}$ limitation led to a high LAR : RLR in L/L seedlings, which was similar to that in $\mathrm{H} / \mathrm{L}$ seedlings, indicating that root length was more sensitive than leaf area to low temperature. As the components of LAR : RLR, leaf-root morphology (SLA : SRL) and leafroot biomass allocation (LMF : RMF) varied in a similar way to their product, except for that LMF : RMF was significantly lower in L/L seedlings than in L/H seedlings. This trend was counteracted by SLA : SRL, resulting in no difference in LAR : RLR.

\section{Effects of $\boldsymbol{T}_{\text {air }}$ and $\boldsymbol{T}_{\text {root }}$ on Carbon and Nutrient Acquisition and Allocation}

At each $T_{\text {root }}$, elevated $T_{\text {air }}$ significantly raised both $\mathrm{R}_{\mathrm{C}}$ and $\mathrm{R}_{\mathrm{N}}$, while elevated $T_{\text {root }}$ only raised $\mathrm{R}_{\mathrm{N}}$ 
different from that of $\mathrm{NAR}_{\mathrm{C}}$. All elevated-temperature treatments significantly increased the $A_{400}$ (net photosynthetic rate) in both true leaves of seedlings (compere $\mathrm{H} / \mathrm{L}, \mathrm{L} / \mathrm{H}$ and $\mathrm{H} / \mathrm{H}$ versus $\mathrm{L} / \mathrm{L}$; Table 4). However, compared to $\mathrm{H} / \mathrm{H}$ seedlings, $T_{\text {root }}$ limitation did not affect the $A_{400}$ in any leaf of $\mathrm{H} / \mathrm{L}$ seedlings, and $T_{\text {air }}$ limitation only decreased the $A_{400}$ in the 2 nd true leaf of $\mathrm{L} / \mathrm{H}$ seedlings. No significant interaction between $T_{\text {air }}$ and $T_{\text {root }}$ was observed in $\mathrm{R}_{\mathrm{C}}, \mathrm{R}_{\mathrm{N}}$ and $\mathrm{NAR}_{\mathrm{C}}($ Figure 4$)$. variation in $R_{C}$, and $S A R_{N}$ contributed a major part of the variation in $R_{N}$.

The value of $R_{C}: R_{N}$ is equal to the ratio of newly gained total carbon to nitrogen per day.

Considering the $\mathrm{R}_{\mathrm{C}}: \mathrm{R}_{\mathrm{N}}$ of $\mathrm{H} / \mathrm{H}$ seedlings as a balanced standard, $T_{\text {air }}$ limitation did not influence the ratio in $\mathrm{L} / \mathrm{H}$ seedlings. This was mainly because of the counteracting effect of decreased root absorption activity (increased $\mathrm{NAR}_{\mathrm{C}}: \mathrm{SAR}_{\mathrm{N}}$ ) and increased root size (decreased $\overline{\mathrm{LAR}}: \overline{\mathrm{RLR}}$ ) (Table 3). $T_{\text {root }}$ limitation raised $R_{C}: R_{N}$ in $H / L$ seedlings by increasing both $N A R_{C}: S A R_{N}$ and $\overline{L A R}: \overline{R L R}$. $T_{\text {all }}$ limitation led to aggregated nitrogen limitation in $\mathrm{L} / \mathrm{L}$ seedlings, similar to that in $\mathrm{H} / \mathrm{L}$ seedlings. This similarity was due to no significant difference in either $N_{A} R_{C}: S_{N}$ or $\overline{L A R}: \overline{R L R}$ between

$258 \mathrm{~L} / \mathrm{L}$ and $\mathrm{H} / \mathrm{L}$ seedlings.

259 The allocation of newly gained carbon and nitrogen to each part of a seedling was not always proportional to that of biomass, and was distinct among different organs (Figure 6A and B, Figure 2). Nitrogen allocation was apparently more flexible than carbon allocation. Newly gained nitrogen was allocated more to new leaf, stem and root than to old leaves. Such trend of heterogeneity was more apparent at high $T_{\text {air }}(\mathrm{H} / \mathrm{H}$ and $\mathrm{H} / \mathrm{L})$. As a result of aggregated nitrogen limitation, $\mathrm{L} / \mathrm{L}$ and $\mathrm{H} / \mathrm{L}$ seedlings had relatively higher carbon concentration and lower nitrogen concentration, and thus higher $\mathrm{C} / \mathrm{N}$ ratios than $\mathrm{L} / \mathrm{H}$ and $\mathrm{H} / \mathrm{H}$ seedlings (Figure 6C, D and $\mathbf{E}$ ). However, the more heterogeneous nitrogen allocation decreased the $\mathrm{C} / \mathrm{N}$ ratios of the second leaf, stem and root (compare $\mathrm{H} / \mathrm{L}$ versus $\mathrm{L} / \mathrm{L}$, or compare $\mathrm{H} / \mathrm{H}$ versus $\mathrm{L} / \mathrm{H}$ ).

The final networks under various conditions were illustrated in Figure 7. As the components of RGR, had a higher direct effect when $T_{\text {air }}$ was changed (Figure 7C, E), and $\mathrm{R}_{\mathrm{N}}$ had a higher direct effect when $T_{\text {root }}$ was changed (Figure 7B, D).

\section{DISCUSSION}

\section{Morphology Responds More than Mass Allocation to Temperature Variation in Both Leaf and Root}

In this study, changes in SLA always accounted for a major part of the temperature-induced variation in LAR, irrespective of $T_{\text {all }}, T_{\text {air }}$ or $T_{\text {root }}$ (Figure 3). Similar results were reported by Loveys et al. (2002) and Poorter et al. (2012), where temperature was managed based on $T_{\text {all }}$ or $T_{\text {air }}$. However, very few studies to date has attempted to examine the $T_{\text {root }}$-induced variation in SLA. According to the results reported by Weih and Karlsson (2001) and Danyagri and Dang (2014), the variation of SLA is more consistent with that of LAR when compared to LMF, indicating that SLA may contribute more to LAR. 
284

285

286

287

288

289

290

291

292

293

294

295

296

297

298

299

300

301

302

303

304

305

306

307

308

309

310

311

312

313

314

315

316

317

318

319

320

321

322

323

324

325

326

327

328

329

the data reported by Tachibana (1982) and Engels et al. (1992). However, this trend is opposite to root response to nutrient regulation reported by Freschet et al. (2015b), that is, RMF contributed more than SRL to the nutrient-induced variation in RLR. One possible reason for the reverse trends is that temperature variation also has significant effects on the hydraulic status of roots (Lee et al., 2004; Lee et al., 2005), which plays an important role in determining root morphology (Wan et al., 1999). Another reason is probably due to the difference in culture medium. It seems that, probably because hydroponics favors root elongation better than soils or sands due to lower mechanical impedance (Bengough and Mullins, 1990), the contribtuion of SRL to RLR was predominent under our hydroponic conditions. However, Engels et al. (1992) found that SRL predominated in RLR under both hydroponic and soil culture conditions, indicating the crucial role played by SRL in determining RLR.

\section{The Role of Root Activity and Size in Nitrogen Uptake Depends on Temperature Management Strategies}

When $T_{\text {air }}$ was elevated alone, NAR $\mathrm{N}_{\mathrm{C}}$ contributed more than LAR to total C assimilation (Figures 4 and 5). However, the contribution of NAR $\mathrm{N}_{\mathrm{C}}$ was reduced when $T_{\text {all }}$ was elevated and was nearly eliminated when $T_{\text {root }}$ was elevated alone, indicating the inhibiting role of elevated $T_{\text {root }}$ in NAR . $\mathrm{NAR}_{\mathrm{C}}$ is the result of leaf photosynthetic rate minus total plant respiration per unit leaf area. Since both leaf photosynthetic capacity and LAR increased at elevated $T_{\text {root }}$ (the higher LAR, the lower leaf mass per unit area; Table 4 and Figure 1), stimulated respiration rate should be mainly responsible for the reduction in $\mathrm{NAR}_{\mathrm{C}}$ at elevated $T_{\text {root }}$. Additionally, because the maintenance respiration rate is generally higher in roots than in leaves (Lambers et al., 1983), and because root respiration increase with increasing temperature (Atkin et al., 2005), the increased RMF : LMF ratio also contributed to the reduction of net carbon accumulation at elevated $T_{\text {root }}$ in this study. For nitrogen absorption, compared with $T_{\text {root }}, T_{\text {air }}$ had only a slight influence on root size but a predominant effect on $\mathrm{SAR}_{\mathrm{N}}$ (Figure 4). Such distinct impacts resulted in that when $T_{\text {air }}$ was changed, $\mathrm{SAR}_{\mathrm{N}}$ contributed more than $\overline{\mathrm{RLR}}$ to the variation of $\mathrm{R}_{\mathrm{N}}$, but this trend was reversed when $T_{\text {root }}$ was changed (Figure 5 and Figure 7). It is generally comprehensible that $T_{\text {air }}$ has less influence on root size than $T_{\text {root }}$, since the $T_{\text {root }}$ has more direct effects on root hydraulic status (Wan et al., 1999; Lee et al., 2004; Lee et al., 2005). Supportive results can be found in the researches of Engels and Marschner (1990) and Larigauderie et al. (1991), although in these studies data were not presented in the form of RLR or root area ratio. The influence of $T_{\text {air }}$ on nutrient uptake is generally considered to be regulated by sugar signals (Stitt and Krapp, 1999). For instance, exogenous application of sugars can increase nitrate reductase activity (Reda, 2015). Moreover, a bZIP transcription factor Arabidopsis ELONGATED HYPOCOTYL5 (HY5) has be reported to mediate sucrose signal and promote root nitrate uptake by activating NRT2.1 (Cerezo et al., 2001; Chen et al., 2016). A previous study (Engels et al. 1992) has reported a promotion effect of elevated shoot base temperature on nutrient translocation rates per unit root fresh weight, but this effect was not examined at elevated $T_{\text {root. }}$ Our observation indicates that the sink-mediated regulation, induced by $T_{\text {air }}$ management, may overtake the direct effects of $T_{\text {root }}$ on length-based SAR ${ }_{N}$. However, Weih and Karlsson (2001) showed that raising $T_{\text {root }}$ was more efficient than raising $T_{\text {air }}$ in increasing nitrogen uptake rate per unit root dry weight. Actually, this result doesn't go against our observation, since the trend was also reversed when transforming length-based $\mathrm{SAR}_{\mathrm{N}}$ into weight-based $\mathrm{SAR}_{\mathrm{N}}$ (Supplementary Table S2) by multiplying SRL in our study. Thus, the significant influence of $T_{\text {root }}$ on SRL may be partly responsible for counteracting the extent of $T_{\text {root }}$ effect on length-based $\mathrm{SAR}_{\mathrm{N}}$.

$\mathrm{R}_{\mathrm{C}}$ and $\mathrm{R}_{\mathrm{N}}$ are additive in affecting $\mathrm{RGR}$, and both are predominant. When $T_{\text {air }}$ was elevated, $\mathrm{R}_{\mathrm{C}}$ and $R_{N}$ were proportionally promoted. However, $R_{C}$ accounted for more variation in RGR than $R_{N}$. This 
is because the concentration of carbon is higher than that of nitrogen in plant tissue. In contrast to the situation at $T_{\text {air }}$, when $T_{\text {root }}$ was elevated, $\mathrm{R}_{\mathrm{C}}$ was not affected, and $\mathrm{R}_{\mathrm{N}}$ (together with other elements absorbed by roots) became the main reason for variation in RGR (Figure 4 and Figure 7). The trends mentioned above were not applicable to the situation at elevated $T_{\text {all }}$.

\section{Adaptive Phenotypic Plasticity in Response to Altered $\boldsymbol{T}_{\text {air }}$ and $\boldsymbol{T}_{\text {root }}$ in Plants}

335 In a heterogeneous temperature ( $T_{\text {air }}$ vs $\left.T_{\text {root }}\right)$ environment, cucumber seedlings tended to invest less

336 biomass and generate relatively smaller organ in the cooler zone. Such passive response would

337

338 potentially strengthen rather than relieve the limitation of the corresponding resource. This trend seems to go against the functional equilibrium hypothesis, that a plant would invest more biomass in the organ responsible for acquiring the most limiting resource (Brouwer, 1963; Freschet et al., 2015b). Based on previous studies regarding biomass allocation, there are both supportive (Tachibana, 1982; Clarkson et al., 1986; Delucia et al., 1992; Danyagri and Dang, 2014) and opposed (Davidson, 1969; Engels and Marschner, 1990; Li et al., 1994; Yan et al., 2012) evidences. It is possible that various factors (e.g. species, temperature, growth medium and ontogenetic stage) may also have impacts on the direction of biomass allocation. For the morphological response, low temperature-induced hydraulic limitation (Murai-Hatano et al., 2008; Wang et al., 2016) and abscisic acid accumulation (Zhang et al., 2008; Ntatsi et al., 2014), which are generally less combined with nutrient and/or light limitation, are both responsible for retarding leaf and root growth (Walter et al., 2009; Pantin et al., 2011). Therefore, in response to temperature variation, changes in the trend of biomass allocation and relative leaf : root size ratio may be more passive rather than adaptive compared with those in respond to nutrient and/or light variation.

According to the above response and the 'balanced growth' hypothesis, $\mathrm{NAR}_{\mathrm{C}}: \mathrm{SAR}_{\mathrm{N}}$ should vary against the trend of LAR : RLR in order to maintain balanced carbon-nutrient acquisition (i.e. $\mathrm{R}_{\mathrm{C}}$ : $\mathrm{R}_{\mathrm{N}}$ ). Actually, in this study, $\mathrm{NAR}_{\mathrm{C}}: \mathrm{SAR}_{\mathrm{N}}$ increased no matter which of $T_{\text {air }}$ and $T_{\text {root }}$ was cooled. At low $T_{\text {air }}$, the higher $\mathrm{NAR}_{\mathrm{C}}: \mathrm{SAR}_{\mathrm{N}}$ counterbalanced the lower LAR : RLR, resulting in a relatively constant $\mathrm{R}_{\mathrm{C}}: \mathrm{R}_{\mathrm{N}}$. At low $T_{\text {root }}$, however, the higher $\mathrm{NAR}_{\mathrm{C}}: \mathrm{SAR}_{\mathrm{N}}$ was accompanied by a higher LAR : RLR, leading to a large increase in $\mathrm{R}_{\mathrm{C}}: \mathrm{R}_{\mathrm{N}}$ (i.e. carbon accumulation or nitrogen limitation). As discussed above, the counteracting effect of root respiration on total carbon acquisition could be one of the main reasons for carbon accumulation when $T_{\text {root }}$ was cooled. In addition, the sugar-induced increase in nitrogen acquisition could be largely inhibited by limited transporter activity (Reay et al., 1999) and root size at low $T_{\text {root }}$ In response to nitrogen limitation, newly gained nitrogen was more unevenly distributed between older leaves and other organs to ensure adequate nitrogen concentration for growth in the latter (L/L vs L/H, H/L vs H/H seedlings, Figure 6).

The $T_{\text {air }}$ and $T_{\text {root }}$ Interactively Determine Root Size

In this study, the $T_{\text {air }}$ and $T_{\text {root }}$ interactively affected RGR, and all root length- and root biomassrelated parameters. The interaction effects on RGR were also reported in Larigauderie et al. (1991) and Weih and Karlsson (2001), which showed that increasing $T_{\text {air }}$ or $T_{\text {root }}$ alone had a greater promotion on RGR than increasing $T_{\text {all }}$. Interestingly, interaction effects were not observed in $\mathrm{R}_{\mathrm{C}}$ and $R_{N}$, neither in LAR and $N A R_{C}$, all of which are components of RGR. Thus the only possible interpretation is that elevated $T_{\text {root }}$ had a weaker effect on uptake of other elements except for nitrogen at high $T_{\text {air }}$ than at low $T_{\text {air }}$. In addition, elevated $T_{\text {root }}$ had a weaker effect on LR length, particularly the length of the second order LRs, at high $T_{\text {air }}$ than at low $T_{\text {air }}$ (Table 1 and Supplementary Figure S1), since the treatment period for seedlings was shorter at high $T_{\text {air }}$ (thus less accumulated $T_{\text {root }}$ ) (KASPAR and BLAND, 1992). This infer that the $T_{\text {air }}$ and $T_{\text {root }}$ interaction effects on root length and root biomass might be further reduced by the initiation and development of 
lateral roots. Generally, the second order LRs were much thinner than main roots and the first order LRs (about $0.2 \mathrm{~mm}$ vs $0.5 \sim 2 \mathrm{~mm}$ ), indicating that elevated $T_{\text {root }}$ led to a much higher SRL at low $T_{\text {air }}$ than at high $T_{\text {air. }}$ This interaction effect can interpret some exceptions in the observed trends, e.g., contributed less than RMF to RLR when $T_{\text {air }}$ was changed at high $T_{\text {root }}$ (Figure 3), and that $T_{\text {air }}$ variation had less influence on LAR : RLR, SLA : SRL and LMF : RMF at low $T_{\text {root }}$ than at high $T_{\text {root }}$ (Table 2).

In this study, cucumber seedlings with the same number of leaves were compared after different treatments, and this was originally designed to avoid ontogenetic effects. The period used for new leaf initiation was changed only by varying $T_{\text {air }}$. This is consistent with the report of Savvides et al. (2016), which showed that the rate of cucumber leaf initiation was completely determined by apical bud temperature independent of the temperature of other plant organs. Although apical bud temperature was not monitored in our experiment, it can be regarded as varying along with $T_{\text {air }}$ rather than $T_{\text {root }}$. Field experiment on tomato also reported that cropping was delayed by low $T_{\text {air }}$ irrespective of $T_{\text {root }}$ (Jones et al., 1978). However, the treatment period aiming for a uniform shoot developmental stage induced ontogenetic drift in roots, as discussed above. Thus, besides plant growth, the distinct influence of $T_{\text {air }}$ and $T_{\text {root }}$ variation on shoot and root development or phenology should also be taken into consideration when designing temperature control strategy for experiment or for protected cultivation.

\section{CONCLUSION}

Our results revealed the distinct effects of $T_{\text {air }}$ and $T_{\text {root }}$ on cucumber seedling growth. The primary influence of cooling $T_{\text {root }}$ on seedling growth was decrease in SRL, which was the main contributor to decrease in RLR. Lower RLR contributed the major part of decrease in total nitrogen acquisition, which finally retarded RGR in seedlings at lower $T_{\text {root }}$. Variation in $T_{\text {root }}$ didn't affect net carbon fixation, although cooling $T_{\text {root }}$ also decreased LAR mainly via reducing SLA. The major effect of decreasing $T_{\text {air }}$ on seedling growth was decrease in the capacities of carbon assimilation in leaves and nitrogen absorption by roots, which contributed more than LAR and RLR to the reduction in total resource acquisition. The ratio of carbon : nitrogen acquisition was maintained at a relatively constant level when $T_{\text {air }}$ was changed, but was increased by decreasing $T_{\text {root }}$. The interactive effect of $T_{\text {air }}$ and $T_{\text {root }}$ was mainly observed on RGR and root growth related variables.

\section{AUTHOR CONTRIBUTIONS}

Conceived and designed the experiments: XW, YT and LG. Performed the experiments: XW. Analysed the data: XW and YT. Wrote the paper: XW and YT.

\section{FUNDING}

This work was supported by the Special Fund for the National Key Research Development Program of China (2016YED201003) and the earmarked fund for the China Agriculture Research System (CARS-25-C-12).

\section{REFERENCES}

Abràmoff, M.D., Magalhães, P.J., and Ram, S.J. (2004). Image processing with ImageJ. Biophotonics international 11(7), 36-42. 
414

415

416

417

418

419

420

421

422

423

424

425

426

427

428

429

430

431

432

433

434

435

436

437

438

439

440

441

442

443

444

445

446

447

448

449

450

451

452

453

454

Ahn, S.J., Im, Y.J., Chung, G.C., Cho, B.H., and Suh, S.R. (1999). Physiological responses of grafted-cucumber leaves and rootstock roots affected by low root temperature. Scientia Horticulturae 81(4), 397-408. doi: Doi 10.1016/S0304-4238(99)00042-4.

Atkin, O.K., Bruhn, D., Hurry, V.M., and Tjoelker, M.G. (2005). The hot and the cold: unravelling the variable response of plant respiration to temperature. Functional Plant Biology 32(2), 87105. doi: 10.1071/fp03176.

Bengough, A.G., and Mullins, C.E. (1990). Mechanical impedance to root growth: a review of experimental techniques and root growth responses. European Journal of Soil Science 41(3), 341-358.

Brouwer, R. (1963). Some aspects of the equilibrium between overground and underground plant parts. Jaarboek van het Instituut voor Biologisch en Scheikundig onderzoek aan Landbouwgewassen 1963, 31-39.

Cerezo, M., Tillard, P., Filleur, S., Muños, S., Daniel-Vedele, F., and Gojon, A. (2001). Major Alterations of the Regulation of Root NO3- Uptake Are Associated with the Mutation of Nrt2.1 and Nrt2.2 Genes in Arabidopsis. Plant Physiology 127(1), 262-271. doi: 10.1104/pp.127.1.262.

Chen, X., Yao, Q., Gao, X., Jiang, C., Harberd, Nicholas P., and Fu, X. (2016). Shoot-to-Root Mobile Transcription Factor HY5 Coordinates Plant Carbon and Nitrogen Acquisition. Current Biology 26(5), 640-646. doi: https://doi.org/10.1016/j.cub.2015.12.066.

Clarkson, D.T., Hopper, M.J., and Jones, L.H.P. (1986). The effect of root temperature on the uptake of nitrogen and the relative size of the root system in Lolium perenne. I. Solutions containing both NH+4 and NO3-. Plant, Cell \& Environment 9(7), 535-545. doi: 10.1111/13653040.ep11616282.

Danyagri, G., and Dang, Q.-L. (2014). Effects of elevated carbon dioxide concentration and soil temperature on the growth and biomass responses of mountain maple (Acer spicatum) seedlings to light availability. Journal of Plant Ecology 7(6), 535-543. doi: 10.1093/jpe/rtt061.

Davidson, R.L. (1969). Effect of root/leaf temperature differentials on root/shoot ratios in some pasture grasses and clover. Annals of Botany 33(131), 561-\&.

Deanedrummond, C.E., and Glass, A.D.M. (1983). Compensatory changes in ion fluxes into barley (Hordeum-vulgare-L cv Betzes) seedlings in response to differential root shoot growth temperature. Journal of Experimental Botany 34(149), 1711-1719. doi: 10.1093/jxb/34.12.1711.

Delucia, E.H., Heckathorn, S.A., and Day, T.A. (1992). Effects of soil temperature on growth, biomass allocation and resource acquisition of Andropogon gerardii Vitman. New Phytologist 120(4), 543-549. doi: 10.1111/j.1469-8137.1992.tb01804.x.

Dewey, D.R., and Lu, K.H. (1959). A Correlation and Path-Coefficient Analysis of Components of Crested Wheatgrass Seed Production1. Agronomy Journal 51(9), 515-518. doi: 10.2134/agronj1959.00021962005100090002x.

Eissenstat, D.M., Wells, C.E., Yanai, R.D., and Whitbeck, J.L. (2000). Building roots in a changing environment: implications for root longevity. New Phytologist 147(1), 33-42. doi: undefined. 
Engels, C., and Marschner, H. (1990). Effect of suboptimal root zone temperatures at varied nutrient supply and shoot meristem temperature on growth and nutrient concentrations in maize seedlings (Zea-mays L). Plant and Soil 126(2), 215-225. doi: 10.1007/bf00012825.

Engels, C., Munkle, L., and Marschner, H. (1992). Effect of root zone temperature and shoot demand on uptake and xylem transport of macronutrients in maize (Zea-mays L). Journal of Experimental Botany 43(249), 537-547. doi: 10.1093/jxb/43.4.537.

Freschet, G.T., Kichenin, E., and Wardle, D.A. (2015a). Explaining within-community variation in plant biomass allocation: a balance between organ biomass and morphology above vs below ground? Journal of Vegetation Science.

Freschet, G.T., Swart, E.M., and Cornelissen, J.H.C. (2015b). Integrated plant phenotypic responses to contrasting above- and below-ground resources: key roles of specific leaf area and root mass fraction. New Phytologist 206(4), 1247-1260. doi: 10.1111/nph.13352.

Gosselin, A., and Trudel, M.J. (1985). Influence of root-zone temperature on growth, development and yield of cucumber plants cv Toska. Plant and Soil 85(3), 327-336.

Hunt, R. (1978). Plant growth analysis. London: Edward Arnold (Publishers) Ltd.

Jones, D.A.G., Sandwell, I., and Talent, C.J.W. (1978). The effect of soil temperature when associated with low air temperatures on the cropping of early tomatoes. Acta Horticulturae (76), 167-171.

Kaspar, T.C., and bland, W.L. (1992). Soil temperature and root growth. Soil Science 154(4), 290299.

Kawasaki, Y., Matsuo, S., Kanayama, Y., and Kanahama, K. (2014). Effect of Root-zone Heating on Root Growth and Activity, Nutrient Uptake, and Fruit Yield of Tomato at Low Air Temperatures. Journal of the Japanese Society for Horticultural Science 83(4), 295-301. doi: 10.2503/jjshs1.MI-001.

Kellermeier, F., Armengaud, P., Seditas, T.J., Danku, J., Salt, D.E., and Amtmann, A. (2014). Analysis of the Root System Architecture of Arabidopsis Provides a Quantitative Readout of Crosstalk between Nutritional Signals. The Plant Cell Online. doi: 10.1105/tpc.113.122101.

Lambers, H., Szaniawski, R.K., and de Visser, R. (1983). Respiration for growth, maintenance and ion uptake. An evaluation of concepts, methods, values and their significance. Physiologia Plantarum 58(4), 556-563. doi: 10.1111/j.1399-3054.1983.tb05742.x.

Larigauderie, A., Ellis, B.A., Mills, J.N., and Kummerow, J. (1991). The Effect of Root and Shoot Temperatures on Growth of Ceanothus greggii Seedlings. Annals of Botany 67(2), 97-101. doi: 10.1093/oxfordjournals.aob.a088121.

Lee, S.H., Chung, G.C., and Steudle, E. (2005). Gating of aquaporins by low temperature in roots of chilling-sensitive cucumber and chilling-tolerant figleaf gourd. J Exp Bot 56(413), 985-995. doi: $10.1093 / \mathrm{jxb} / \mathrm{eri} 092$.

Lee, S.H., Singh, A.P., Chung, G.C., Ahn, S.J., Noh, E.K., and Steudle, E. (2004). Exposure of roots of cucumber (Cucumis sativus) to low temperature severely reduces root pressure, hydraulic conductivity and active transport of nutrients. Physiol Plant 120(3), 413-420. doi: 10.1111/j.0031-9317.2004.00248.x.

Li, X.M., Feng, Y.S., and Boersma, L. (1994). Partition of photosynthates between shoot and root in spring wheat (Triticum-aestivum $\mathrm{L}$ ) as a function of soil-water potential and root temperature. Plant and Soil 164(1), 43-50. doi: 10.1007/bf00010109. 
Loveys, B.R., Scheurwater, I., Pons, T.L., Fitter, A.H., and Atkin, O.K. (2002). Growth temperature influences the underlying components of relative growth rate: an investigation using inherently fast- and slow-growing plant species. Plant, Cell \& Environment 25(8), 975-988. doi: 10.1046/j.1365-3040.2002.00879.x.

Maire, V., Gross, N., Hill, D., Martin, R., Wirth, C., Wright, I.J., et al. (2013). Disentangling Coordination among Functional Traits Using an Individual-Centred Model: Impact on Plant Performance at Intra- and Inter-Specific Levels. PLOS ONE 8(10), e77372. doi: 10.1371/journal.pone.0077372.

Murai-Hatano, M., Kuwagata, T., Sakurai, J., Nonami, H., Ahamed, A., Nagasuga, K., et al. (2008). Effect of low root temperature on hydraulic conductivity of rice plants and the possible role of aquaporins. Plant and Cell Physiology 49(9), 1294-1305. doi: 10.1093/pcp/pen104.

Nagel, K.A., Kastenholz, B., Jahnke, S., van Dusschoten, D., Aach, T., MÂ“'̂̂'hlich, M., et al. (2009). Temperature responses of roots: impact on growth, root system architecture and implications for phenotyping. Functional Plant Biology 36(11), 947-959. doi: doi:10.1071/FP09184.

Ntatsi, G., Savvas, D., Huntenburg, K., Druege, U., Hincha, D.K., Zuther, E., et al. (2014). A study on $\mathrm{ABA}$ involvement in the response of tomato to suboptimal root temperature using reciprocal grafts with notabilis, a null mutant in the ABA-biosynthesis gene LeNCED1. Environmental and Experimental Botany 97, 11-21. doi: 10.1016/j.envexpbot.2013.09.011.

Pantin, F., Simonneau, T., Rolland, G., Dauzat, M., and Muller, B. (2011). Control of Leaf Expansion: A Developmental Switch from Metabolics to Hydraulics. Plant Physiology 156(2), 803-815. doi: 10.1104/pp.111.176289.

Poire, R., Schneider, H., Thorpe, M.R., Kuhn, A.J., Schurr, U., and Walter, A. (2010). Root cooling strongly affects diel leaf growth dynamics, water and carbohydrate relations in Ricinus communis. Plant Cell and Environment 33(3), 408-417. doi: 10.1111/j.13653040.2009.02090.x.

Poorter, H., Niklas, K.J., Reich, P.B., Oleksyn, J., Poot, P., and Mommer, L. (2012). Biomass allocation to leaves, stems and roots: meta-analyses of interspecific variation and environmental control. New Phytologist 193(1), 30-50. doi: 10.1111/j.14698137.2011.03952.x.

Reay, D.S., Nedwell, D.B., Priddle, J., and Ellis-Evans, J.C. (1999). Temperature Dependence of Inorganic Nitrogen Uptake: Reduced Affinity for Nitrate at Suboptimal Temperatures in Both Algae and Bacteria. Applied and Environmental Microbiology 65(6), 2577-2584.

Reda, M. (2015). Response of nitrate reductase activity and NIA genes expression in roots of Arabidopsis hxkl mutant treated with selected carbon and nitrogen metabolites. Plant Science 230, 51-58. doi: https://doi.org/10.1016/j.plantsci.2014.10.008.

Rees, M., Osborne, C.P., Woodward, F.I., Hulme, S.P., Turnbull, L.A., and Taylor, S.H. (2010). Partitioning the Components of Relative Growth Rate: How Important Is Plant Size Variation? American Naturalist 176(6), E152-E161. doi: 10.1086/657037.

Ryser, P., and Eek, L. (2000). Consequences of phenotypic plasticity vs. interspecific differences in leaf and root traits for acquisition of aboveground and belowground resources. American Journal of Botany 87(3), 402-411. 
Savvides, A., Dieleman, J.A., van Ieperen, W., and Marcelis, L.F.M. (2016). A unique approach to demonstrating that apical bud temperature specifically determines leaf initiation rate in the dicot Cucumis sativus. Planta 243(4), 1071-1079. doi: 10.1007/s00425-015-2464-4.

Shipley, B., and Meziane, D. (2002). The balanced-growth hypothesis and the allometry of leaf and root biomass allocation. Functional Ecology 16(3), 326-331.

Stitt, M., and Krapp, A. (1999). The interaction between elevated carbon dioxide and nitrogen nutrition: the physiological and molecular background. Plant, Cell \& Environment 22(6), 583-621. doi: 10.1046/j.1365-3040.1999.00386.x.

Tachibana, S. (1982). Comparison of effects of root temperature on the growth and mineral-nutrition of cucumber cultivars and figleaf gourd. Journal of the Japanese Society for Horticultural Science 51(3), 299-308.

Tachibana, S. (1987). Effect of root temperature on the rate of water and nutrient absorption in cucumber cultivars and figleaf gourd. Journal of the Japanese Society for Horticultural Science 55(4), 461-467.

Teitel, M., Segal, I., Shklyar, A., and Barak, M. (1999). A comparison between pipe and air heating methods for greenhouses. Journal of Agricultural Engineering Research 72(3), 259-273.

Terashima, I., Noguchi, K., Itoh-Nemoto, T., Park, Y.M., Kubo, A., and Tanaka, K. (1998). The cause of PSI photoinhibition at low temperatures in leaves of Cucumis sativus, a chillingsensitive plant. Physiologia Plantarum 103(3), 295-303. doi: 10.1034/j.13993054.1998.1030301.x.

Urrestarazu, M., del Carmen Salas, M., Valera, D., Gómez, A., and Mazuela, P.C. (2008). Effects of Heating Nutrient Solution on Water and Mineral Uptake and Early Yield of Two Cucurbits under Soilless Culture. Journal of Plant Nutrition 31(3), 527-538. doi: 10.1080/01904160801895068.

Walter, A., Silk, W.K., and Schurr, U. (2009). Environmental Effects on Spatial and Temporal Patterns of Leaf and Root Growth. Annual Review of Plant Biology 60(1), 279-304. doi: doi:10.1146/annurev.arplant.59.032607.092819.

Wan, X., Landhäusser, S.M., Zwiazek, J.J., and Lieffers, V.J. (1999). Root water flow and growth of aspen (Populus tremuloides) at low root temperatures. Tree Physiology 19(13), 879-884. doi: 10.1093/treephys/19.13.879.

Wang, X.Z., Zhang, W.H., Miao, Y.X., and Gao, L.H. (2016). Root-Zone Warming Differently Benefits Mature and Newly Unfolded Leaves of Cucumis sativus L. Seedlings under SubOptimal Temperature Stress. Plos One 11(5), 20. doi: 10.1371/journal.pone.0155298.

Weih, M., and Karlsson, P.S. (2001). Growth response of Mountain birch to air and soil temperature: is increasing leaf-nitrogen content an acclimation to lower air temperature? New Phytologist 150(1), 147-155. doi: 10.1046/j.1469-8137.2001.00078.x.

Welbank, P.J. (1962). The Effects of Competition with Agropyron repens and of Nitrogen-and Water Supply on the Nitrogen Content of Impatiens parviflora. Annals of Botany 26(3), 359-373. doi: 10.1093/oxfordjournals.aob.a083800.

Yamazaki, K. (1982). Yōeki saibai zenpen. Tokyo: Hakuyūsha.

Yan, Q.Y., Duan, Z.Q., Mao, J.D., Li, X., and Dong, F. (2012). Effects of root-zone temperature and $\mathrm{N}, \mathrm{P}$, and $\mathrm{K}$ supplies on nutrient uptake of cucumber (Cucumis sativus L.) seedlings in 
hydroponics. Soil Science and Plant Nutrition 58(6), 707-717. doi: 10.1080/00380768.2012.733925.

Zhang, Y.P., Qiao, Y.X., Zhang, Y.L., Zhou, Y.H., and Yu, J.Q. (2008). Effects of root temperature on leaf gas exchange and xylem sap abscisic acid concentrations in six Cucurbitaceae species. Photosynthetica 46(3), 356-362.

\section{FIGURE CAPTIONS}

Figure 1. Responses of leaf and root relative size, morphology and biomass allocation to air temperature $\left(T_{\text {air }}\right)$ variation (solid lines) and root-zone temperature $\left(T_{\text {root }}\right)$ variation (dashed lines). Each variable is expressed on a $\log _{2}$-scale. Data points and error bars are means \pm standard error $(\mathrm{n}=$ 7). Different letters besides each point denote significance at $P<0.05$ by Tukey's HSD-test. The significance (*, $P<0.05$; *** $P<0.001$; ns, not significant) of interactions between $T_{\text {air }}$ and $T_{\text {root }}$ is displayed in each panel. L/L, low $T_{\text {air }} /$ low $T_{\text {root }} ; \mathrm{L} / \mathrm{H}$, low $T_{\text {air }} / \mathrm{high} T_{\text {root }} ; \mathrm{H} / \mathrm{L}$, high $T_{\text {air }} /$ low $T_{\text {root }} ; \mathrm{H} / \mathrm{H}$, high $T_{\text {air }} /$ high $T_{\text {root. }}$ The data (in number) of this figure are exhibited in Supplementary Table S1.

Figure 2. Allocation ratios of biomass increment in different organs during treatment. Boxes and error bars are means \pm standard error $(n=7)$. Different letters besides each point denote significance at $P<0.05$ by Tukey's HSD-test. LAR, leaf area ratio; RLR, root length ratio; SLA, specific leaf area; SRL, specific root length; LMF, leaf mass fraction; RMF, root mass fraction. L/L, low $T_{\text {air }} /$ low $T_{\text {root }} ; \mathrm{L} / \mathrm{H}$, low $T_{\text {air }} /$ high $T_{\text {root }} ; \mathrm{H} / \mathrm{L}$, high $T_{\text {air }} /$ low $T_{\text {root }} ; \mathrm{H} / \mathrm{H}$, high $T_{\text {air }} /$ high $T_{\text {root }}$.

Figure 3. Relative contribution of leaf and root biomass allocation (LMF or RMF) and morphology (SLA or SRL) variables to the total variation in LAR and RLR. The category " $T_{\text {all }}$ Variation" refers to $\mathrm{L} / \mathrm{L}$ versus $\mathrm{H} / \mathrm{H}$; " $T_{\text {root }}$ Variation" refers to the mean value of $\mathrm{L} / \mathrm{L}$ versus $\mathrm{L} / \mathrm{H}$ and $\mathrm{H} / \mathrm{L}$ versus $\mathrm{H} / \mathrm{H}$; " $T_{\text {air }}$ Variation" refers to the mean value of $\mathrm{L} / \mathrm{L}$ versus $\mathrm{H} / \mathrm{L}$ and $\mathrm{L} / \mathrm{H}$ versus $\mathrm{H} / \mathrm{H}$. Specially, the inserted viewport displays $\mathrm{L} / \mathrm{L}$ versus $\mathrm{H} / \mathrm{L}$ (sub-optimal $T_{\text {root }}$ ) and $\mathrm{L} / \mathrm{H}$ versus $\mathrm{H} / \mathrm{H}$ (optimal $T_{\text {root}}$ ) respectively, due to the significant difference between the two conditions. LAR, leaf area ratio; RLR, root length ratio. $\mathrm{L} / \mathrm{L}$, low $T_{\text {air }} /$ low $T_{\text {root }} ; \mathrm{L} / \mathrm{H}$, low $T_{\text {air }} /$ high $T_{\text {root }} ; \mathrm{H} / \mathrm{L}$, high $T_{\text {air }} /$ low $T_{\text {root }} ; \mathrm{H} / \mathrm{H}$, high $T_{\text {air }} /$ high $T_{\text {root }}$.

Figure 4. Responses of leaf and root size and assimilation/absorption rate to air temperature $\left(T_{\text {air }}\right)$ variation (solid lines) and root-zone temperature $\left(T_{\text {root }}\right)$ variation (dashed lines). Each variable is expressed on a $\log _{2}$-scale. Data points and error bars are means \pm standard error $(n=7)$. Different letters besides each point denote significance at $P<0.05$ by Tukey's HSD-test. The significance $(*$, $P<0.05$; ** $P<0.01$; *** $P<0.001$; ns, not significant) of interactions between $T_{\text {air }}$ and $T_{\text {root }}$ is displayed in each panel. L/L, low $T_{\text {air }} /$ low $T_{\text {root }} ; \mathrm{L} / \mathrm{H}$, low $T_{\text {air }} / \mathrm{high} T_{\text {root }} ; \mathrm{H} / \mathrm{L}$, high $T_{\text {air }} /$ low $T_{\text {root }} ; \mathrm{H} / \mathrm{H}$, high $T_{\text {air }} /$ high $T_{\text {root. }}$ The data (in number) of this figure are exhibited in Supplementary Table S2.

Figure 5. Relative contribution of leaf and root assimilation/absorption activity $\left(\mathrm{NAR}_{\mathrm{C}}\right.$ or $\left.\mathrm{SAR}_{\mathrm{N}}\right)$ and size ( $\overline{\mathrm{LAR}}$ or $\overline{\mathrm{RLR}}$ ) variables to the total variation in $\mathrm{R}_{\mathrm{C}}$ and $\mathrm{R}_{\mathrm{N}}$. The category " $T_{\text {all }}$ Variation" refers to $\mathrm{L} / \mathrm{L}$ versus $\mathrm{H} / \mathrm{H}$; " $T_{\text {root }}$ Variation" refers to the mean value of $\mathrm{L} / \mathrm{L}$ versus $\mathrm{L} / \mathrm{H}$ and $\mathrm{H} / \mathrm{L}$ versus $\mathrm{H} / \mathrm{H}$; " $T_{\text {air }}$ Variation" refers to the mean value of $\mathrm{L} / \mathrm{L}$ versus $\mathrm{H} / \mathrm{L}$ and $\mathrm{L} / \mathrm{H}$ versus $\mathrm{H} / \mathrm{H}$. n/a, not applicable, as no more than $15 \%$ variation in $\mathrm{R}_{\mathrm{C}}$ was observed when changing $T_{\text {root }} \mathrm{L} / \mathrm{L}$, low $T_{\text {air }} /$ low $T_{\text {root }} ; \mathrm{L} / \mathrm{H}$, low $T_{\text {air }} /$ high $T_{\text {root }} ; \mathrm{H} / \mathrm{L}$, high $T_{\text {air }} /$ low $T_{\text {root }} ; \mathrm{H} / \mathrm{H}$, high $T_{\text {air }} /$ high $T_{\text {root }}$. 
622 Figure 6. Relative allocation of carbon (A) and nitrogen (B), relative concentration of carbon (C) and

623 nitrogen $(\mathrm{D})$, and relative $\mathrm{C} / \mathrm{N}$ ratio $(\mathrm{E})$ in each part of the treated seedlings. $(\mathrm{A})(\mathrm{B})$ relative

624 allocation was calculated through dividing the ratio of carbon or nitrogen allocated to each part by

625 the ratio of biomass allocated to correspond part. (C)(D) (E) relative values was calculated through

626

627 dividing the value in each part by those in the seedlings before treatment. Specially, values in the second true leaves were divided by those in the first true leaves of un-treated seedlings. Negative

628 value of relative allocation indicates net efflux rather than influx of element in the correspond part of plant during treatment. L/L, low $T_{\text {air }} /$ low $T_{\text {root }} ; \mathrm{L} / \mathrm{H}$, low $T_{\text {air }} /$ high $T_{\text {root }} ; \mathrm{H} / \mathrm{L}$, high $T_{\text {air }} /$ low $T_{\text {root }} ; \mathrm{H} / \mathrm{H}$, high $T_{\text {air }} /$ high $T_{\text {root }}$. The data (in number) of this figure and biomass allocation are exhibited in

\section{Supplementary Table S3.}

632 Figure 7. Networks of relative contribution among leaf and root morphology, biomass allocation, 633 size and capacity variables, and direct path coefficients of carbon and nitrogen acquisition rate to 634 relative growth rate under different conditions of temperature variation. (A) L/L vs H/H seedlings, 635 overall warmed or cooled; (B) L/L vs L/H seedlings, only root-zone was warmed; (C) L/L vs H/L 636 seedlings, only air was warmed; (D) $\mathrm{H} / \mathrm{H}$ vs $\mathrm{H} / \mathrm{L}$ seedlings, only root-zone was cooled; (E) $\mathrm{H} / \mathrm{H}$ vs $637 \mathrm{~L} / \mathrm{H}$ seedlings, only air was cooled. L/L, low $T_{\text {air }} /$ low $T_{\text {root }} ; \mathrm{L} / \mathrm{H}$, low $T_{\text {air }} /$ high $T_{\text {root }} ; \mathrm{H} / \mathrm{L}$, high $T_{\text {air }} / \mathrm{low}$ $638 T_{\text {root }} ; \mathrm{H} / \mathrm{H}$, high $T_{\text {air }} /$ high $T_{\text {root }}$.

\section{TABLES}

640 Table 1. Plant growth parameters of seedlings before and after different temperature treatments.

641 Means with different letters are significantly different $(P<0.05, \mathrm{n}=6-7)$ by Tukey HSD. Source of 642 variation: $F$ values and significance $(* P<0.05$; ** $P<0.01$; *** $P<0.001$; ns, not significant) of

643 air temperature $\left(T_{\text {air }}\right)$, root-zone temperature $\left(T_{\text {root }}\right)$ and $T_{\text {air }} \times T_{\text {root. }} \mathrm{L} / \mathrm{L}$, low $T_{\text {air }} /$ low $T_{\text {root }} ; \mathrm{L} / \mathrm{H}$, low $644 T_{\text {air }} /$ high $T_{\text {root }} ; \mathrm{H} / \mathrm{L}$, high $T_{\text {air }} /$ low $T_{\text {root }} ; \mathrm{H} / \mathrm{H}$, high $T_{\text {air }} /$ high $T_{\text {root }}$.

\begin{tabular}{|c|c|c|c|c|c|c|c|c|c|c|c|c|}
\hline \multirow{2}{*}{$\begin{array}{l}\text { Treatment } \\
\text { Before treatment }\end{array}$} & \multicolumn{2}{|c|}{$\begin{array}{l}\text { Total dry } \\
\text { mass /mg }\end{array}$} & \multicolumn{2}{|c|}{$\underset{/ \mathrm{mg} \cdot \mathrm{g}^{-1} \cdot \mathrm{d}^{-1}}{\mathrm{RGR}}$} & \multicolumn{2}{|c|}{$\begin{array}{l}\text { Leaf dry } \\
\text { mass /mg }\end{array}$} & \multicolumn{2}{|c|}{$\begin{array}{l}\text { Root dry } \\
\text { mass /mg }\end{array}$} & \multicolumn{2}{|c|}{$\begin{array}{l}\text { Total leaf } \\
\text { area } / \mathrm{cm}^{2}\end{array}$} & \multicolumn{2}{|c|}{$\begin{array}{l}\text { Total root } \\
\text { length } / \mathrm{m}\end{array}$} \\
\hline & 183 & & - & & 135 & & 18.9 & & 51.9 & & 5.89 & \\
\hline $\mathrm{L} / \mathrm{L}$ & 481 & $\mathrm{~b}$ & 96 & d & 342 & $\mathrm{~b}$ & 46.5 & $\mathrm{~b}$ & 95.1 & $\mathrm{c}$ & 7.44 & $\mathrm{c}$ \\
\hline $\mathrm{L} / \mathrm{H}$ & 599 & $\mathrm{a}$ & 118 & $\mathrm{c}$ & 396 & $\mathrm{a}$ & 80.1 & $\mathrm{a}$ & 139.3 & $\mathrm{a}$ & 27.48 & $\mathrm{a}$ \\
\hline $\mathrm{H} / \mathrm{L}$ & 358 & d & 134 & $\mathrm{~b}$ & 265 & $\mathrm{c}$ & 32.0 & $d$ & 92.0 & $\mathrm{c}$ & 6.71 & $\mathrm{~d}$ \\
\hline $\mathrm{H} / \mathrm{H}$ & 394 & c & 153 & $\mathrm{a}$ & 279 & $\mathrm{c}$ & 41.7 & $\mathrm{c}$ & 116.8 & $\mathrm{~b}$ & 13.31 & $\mathrm{~b}$ \\
\hline \multicolumn{13}{|l|}{ Source of variation } \\
\hline$T_{\text {air }}$ & 409 & $* * *$ & 577 & $* * *$ & 341 & $* * *$ & 369 & $* * *$ & 129 & $* * *$ & 453 & $* * *$ \\
\hline$T_{\text {root }}$ & 79 & $* * *$ & 191 & $* * *$ & 37 & $* * *$ & 228 & $* * *$ & 1129 & $* * *$ & 2612 & $* * *$ \\
\hline$T_{\text {air }} \times T_{\text {root }}$ & 12 & $* *$ & 9 & $* *$ & 8 & $* *$ & 27 & $* * *$ & 60 & $* * *$ & 254 & $* * *$ \\
\hline \multirow[b]{2}{*}{ Treatment } & \multicolumn{6}{|c|}{ Leaf area $/ \mathrm{cm}^{2}$} & \multicolumn{6}{|c|}{ Root length /cm } \\
\hline & \multicolumn{2}{|c|}{ Cotyledon } & \multicolumn{2}{|c|}{$\begin{array}{c}\text { 1st true } \\
\text { leaf }\end{array}$} & \multicolumn{2}{|c|}{$\begin{array}{c}\text { 2nd true } \\
\text { leaf }\end{array}$} & \multicolumn{2}{|c|}{ Main root } & \multicolumn{2}{|c|}{$\begin{array}{l}\text { 1st class } \\
\text { LR }\end{array}$} & \multicolumn{2}{|c|}{$\begin{array}{c}\text { 2nd class } \\
\text { LR }\end{array}$} \\
\hline Before treatment & 18.2 & & 33.7 & & - & & 29.7 & & 363 & & 197 & \\
\hline $\mathrm{L} / \mathrm{L}$ & 20.2 & $\mathrm{a}$ & 42.7 & $\mathrm{c}$ & 32.2 & $\mathrm{c}$ & 29.9 & $\mathrm{~b}$ & 391 & $\mathrm{c}$ & 323 & $\mathrm{c}$ \\
\hline $\mathrm{L} / \mathrm{H}$ & 19.7 & $\mathrm{a}$ & 54.8 & $\mathrm{a}$ & 64.9 & $\mathrm{a}$ & 40.7 & $\mathrm{a}$ & 954 & $\mathrm{a}$ & 1754 & $\mathrm{a}$ \\
\hline $\mathrm{H} / \mathrm{L}$ & 19.5 & $\mathrm{a}$ & 39.4 & $\mathrm{~d}$ & 33.1 & $\mathrm{c}$ & 29.4 & $\mathrm{~b}$ & 367 & $\mathrm{c}$ & 275 & $\mathrm{c}$ \\
\hline $\mathrm{H} / \mathrm{H}$ & 19.7 & $\mathrm{a}$ & 50.8 & $\mathrm{~b}$ & 46.2 & $\mathrm{~b}$ & 34.5 & $a b$ & 567 & $\mathrm{~b}$ & 731 & $\mathrm{~b}$ \\
\hline
\end{tabular}




\begin{tabular}{lrlrlrlrlrrrrr}
\hline Source of variation & & & & & & & & & & & & & \\
$T_{\text {air }}$ & 0.566 & $\mathrm{~ns}$ & 31 & $* * *$ & 113 & $* * *$ & 4.4 & $*$ & 38 & $* * *$ & 29 & $* * *$ \\
$T_{\text {root }}$ & 0.203 & $\mathrm{~ns}$ & 330 & $* * *$ & 1236 & $* * *$ & 27.5 & $* * *$ & 187 & $* * *$ & 193 & $* * *$ \\
$T_{\text {air }} \times T_{\text {root }}$ & 0.848 & $\mathrm{~ns}$ & 0 & $\mathrm{~ns}$ & 154 & $* * *$ & 3.0 & $\mathrm{~ns}$ & 21 & $* * *$ & 13 & $* *$ \\
\hline
\end{tabular}

646 Table 2. Ratios of leaf : root morphological, biomass fraction and size parameters of seedlings before 647 and after different temperature treatments. Means with different letters are significantly different $(P<$ $6480.05, \mathrm{n}=7)$ by Tukey HSD. Source of variation: $F$ values and significance $(* * P<0.01 ; * * * P<$

$6490.001)$ of air temperature $\left(T_{\text {air }}\right)$, root-zone temperature $\left(T_{\text {root }}\right)$ and $T_{\text {air }} \times T_{\text {root. }}$ SLA, specific leaf area;

650 SRL, specific root length; LMF, leaf mass fraction; RMF, root mass fraction; LAR, leaf area ratio; 651 RLR, root length ratio. $\mathrm{L} / \mathrm{L}$, low $T_{\text {air }} /$ low $T_{\text {root }} ; \mathrm{L} / \mathrm{H}$, low $T_{\text {air }} /$ high $T_{\text {root }} ; \mathrm{H} / \mathrm{L}$, high $T_{\text {air }} /$ low $T_{\text {root }} ; \mathrm{H} / \mathrm{H}$, 652 high $T_{\text {air }} /$ high $T_{\text {root. }}$

\begin{tabular}{|c|c|c|c|}
\hline Treatment & $\begin{array}{l}\text { SLA : SRL } \\
/ \mathrm{cm}^{2} \cdot \mathrm{m}^{-1}\end{array}$ & $\begin{array}{l}\text { LMF : } \\
\text { RMF }\end{array}$ & $\begin{array}{l}\text { LAR : RLR } \\
\quad / \mathrm{cm}^{2} \cdot \mathrm{m}^{-1}\end{array}$ \\
\hline Before treatment & 1.24 & 7.12 & 8.82 \\
\hline $\mathrm{L} / \mathrm{L}$ & $1.74 \mathrm{a}$ & $7.36 \mathrm{~b}$ & $12.80 \mathrm{a}$ \\
\hline $\mathrm{L} / \mathrm{H}$ & $1.03 \mathrm{c}$ & $4.97 \mathrm{~d}$ & $5.08 \mathrm{c}$ \\
\hline $\mathrm{H} / \mathrm{L}$ & 1.66 & 8.28 & 13.75 \\
\hline $\mathrm{H} / \mathrm{H}$ & 1.31 & 6.71 & 8.79 \\
\hline
\end{tabular}

Source of variation

\begin{tabular}{lrlrlrl}
$T_{\text {air }}$ & 12 & $* *$ & 84 & $* * *$ & 245 & $* * *$ \\
$T_{\text {root }}$ & 179 & $* * *$ & 175 & $* * *$ & 1201 & $* * *$ \\
$T_{\text {air }} \times T_{\text {root }}$ & 26 & $* * *$ & 16 & $* * *$ & 146 & $* * *$ \\
\hline
\end{tabular}

654 Table 3. Ratios of leaf : root average size and resource acquiring capacity, and relative carbon : 655 nitrogen accumulation rate of seedlings during different temperature treatments. Means with different 656 letters are significantly different $(P<0.05, \mathrm{n}=7)$ by Tukey HSD. Source of variation: $F$ values and 657 significance (** $P<0.01$; *** $P<0.001$; ns, not significant) of air temperature $\left(T_{\text {air }}\right)$, root-zone 658 temperature $\left(T_{\text {root }}\right)$ and $T_{\text {air }} \times T_{\text {root. }} \mathrm{L} / \mathrm{L}$, low $T_{\text {air }} /$ low $T_{\text {root }} ; \mathrm{L} / \mathrm{H}$, low $T_{\text {air }} / \mathrm{high} T_{\text {root}} ; \mathrm{H} / \mathrm{L}$, high $T_{\text {air }} / \mathrm{low}$ $659 T_{\text {root }} ; \mathrm{H} / \mathrm{H}$, high $T_{\text {air }} /$ high $T_{\text {root }}$.

\begin{tabular}{lcccccc}
\hline Treatment & $\begin{array}{c}\mathrm{LAR}: \overline{\mathrm{RLR}}, \\
/ \mathrm{cm}^{2} \cdot \mathrm{m}^{-1}\end{array}$ & $\begin{array}{r}\mathrm{NAR}_{\mathrm{C}}: \\
\mathrm{SAR}_{\mathrm{N}}\end{array}$ & $\mathrm{R}_{\mathrm{C}}: \mathrm{R}_{\mathrm{N}}$ \\
\hline $\mathrm{L} / \mathrm{L}$ & 10.76 & $\mathrm{a}$ & 1.05 & $\mathrm{a}$ & 11.33 & $\mathrm{a}$ \\
$\mathrm{L} / \mathrm{H}$ & 6.32 & $\mathrm{c}$ & 1.09 & $\mathrm{a}$ & 6.87 & $\mathrm{~b}$ \\
$\mathrm{H} / \mathrm{L}$ & 11.15 & $\mathrm{a}$ & 1.10 & $\mathrm{a}$ & 12.23 & $\mathrm{a}$ \\
$\mathrm{H} / \mathrm{H}$ & 8.80 & $\mathrm{~b}$ & 0.82 & $\mathrm{~b}$ & 7.17 & $\mathrm{~b}$ \\
\hline
\end{tabular}




\begin{tabular}{lrlllrl} 
Source of variation & & & & & & \\
$T_{\text {air }}$ & 100 & $* * *$ & 14 & $* *$ & 4 & $\mathrm{~ns}$ \\
$T_{\text {root }}$ & 439 & $* * *$ & 14 & $* * *$ & 317 & $* * *$ \\
$T_{\text {air }} \times T_{\text {root }}$ & 65 & $* * *$ & 23 & $* * *$ & 0 & $\mathrm{~ns}$ \\
\hline
\end{tabular}

660

661 Table 4. Net photosynthetic rates of cucumber true leaves at $400 \mu \mathrm{mol} \mathrm{CO} \cdot \mathrm{mol}^{-1}$ reference $\mathrm{CO}_{2}$

662 concentration. Means with different letters are significantly different $(P<0.05, \mathrm{n}=7)$ by Tukey HSD.

663 Source of variation: $F$ values and significance $(* * P<0.01$; *** $P<0.001)$ of air temperature $\left(T_{\text {air }}\right)$,

664 root-zone temperature $\left(T_{\text {root }}\right)$ and $T_{\text {air }} \times T_{\text {root. }} \mathrm{L} / \mathrm{L}$, low $T_{\text {air }} /$ low $T_{\text {root }} ; \mathrm{L} / \mathrm{H}$, low $T_{\text {air }} /$ high $T_{\text {root }} ; \mathrm{H} / \mathrm{L}$, high

$665 T_{\text {air }} /$ low $T_{\text {root }} ; \mathrm{H} / \mathrm{H}$, high $T_{\text {air }} /$ high $T_{\text {root }}$.

\begin{tabular}{lrlrl}
\hline & \multicolumn{4}{c}{$A_{400}$} \\
Treatment & \multicolumn{4}{c}{$\mu \mathrm{mol} \mathrm{CO} \mathrm{CO}_{2} \cdot \mathrm{m}^{-1} \cdot \mathrm{s}^{-1}$} \\
\cline { 2 - 5 } & \multicolumn{2}{c}{$1 \mathrm{st}$ leaf } & \multicolumn{2}{c}{ 2nd leaf } \\
\hline $\mathrm{L} / \mathrm{L}$ & 9.6 & $\mathrm{~b}$ & 9.3 & $\mathrm{c}$ \\
$\mathrm{L} / \mathrm{H}$ & 18.7 & $\mathrm{a}$ & 13.2 & $\mathrm{~b}$ \\
$\mathrm{H} / \mathrm{L}$ & 20.8 & $\mathrm{a}$ & 16.7 & $\mathrm{a}$ \\
$\mathrm{H} / \mathrm{H}$ & 19.0 & $\mathrm{a}$ & 18.3 & $\mathrm{a}$ \\
\hline Source of variation & & & \\
$T_{\text {air }}$ & 54 & $* * *$ & 207 & $* * *$ \\
$T_{\text {root }}$ & 30 & $* * *$ & 40 & $* * *$ \\
$T_{\text {air }} \times T_{\text {root }}$ & 66 & $* * *$ & 14 & $* *$ \\
\hline
\end{tabular}

666 

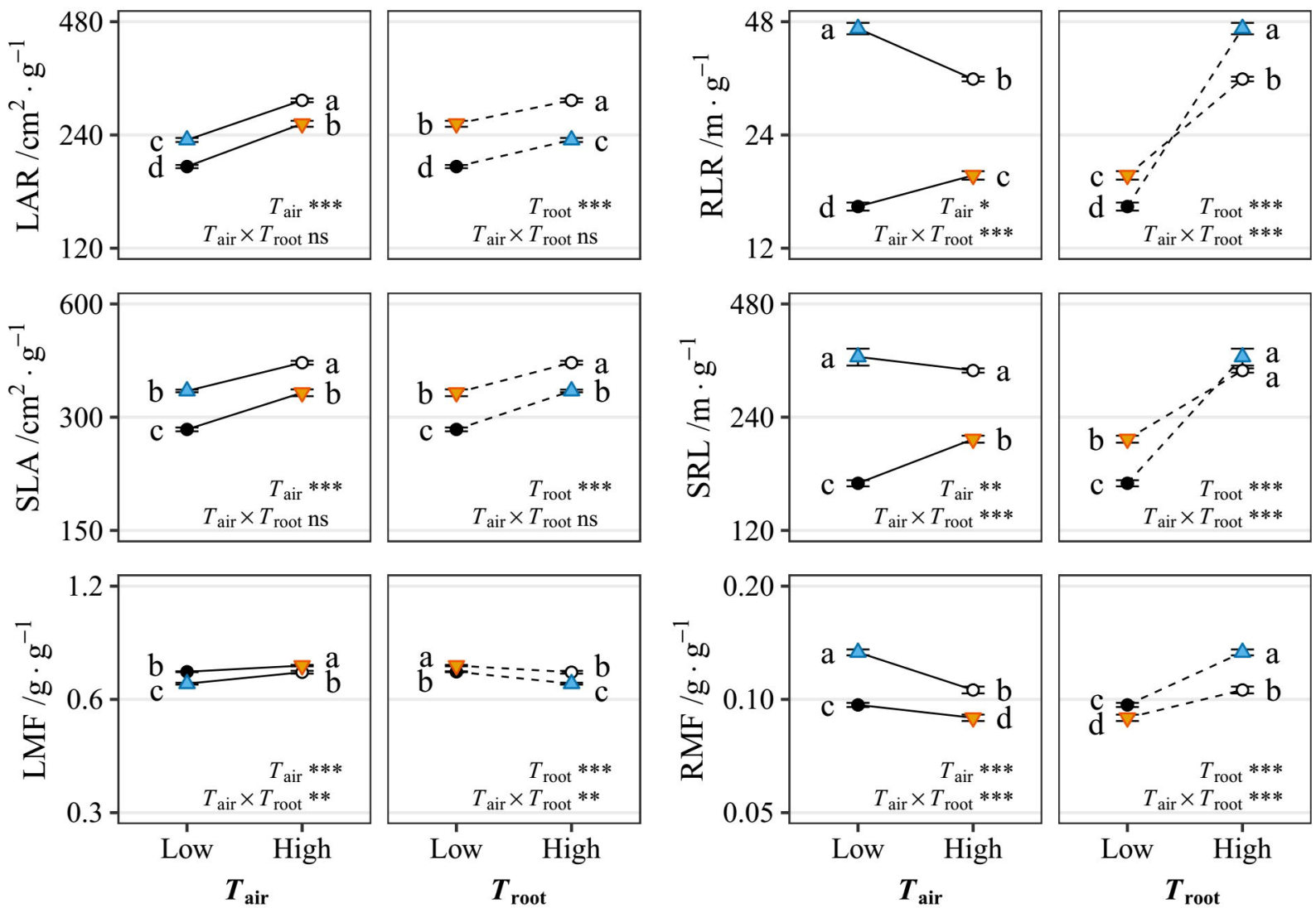

- $\mathrm{L} / \mathrm{L} \quad \Delta \mathrm{L} / \mathrm{H} \quad \nabla \mathrm{H} / \mathrm{L} \quad \circ \mathrm{H} / \mathrm{H}$ 


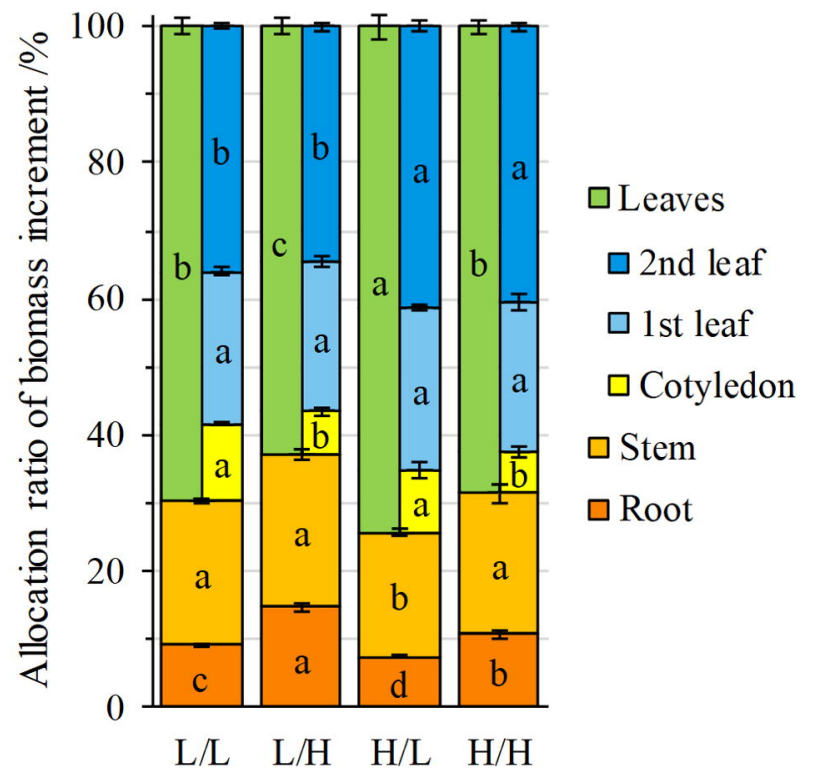


$T_{\text {all }}$ Variation $\quad T_{\text {root }}$ Variation $\quad T_{\text {air Variation }}$

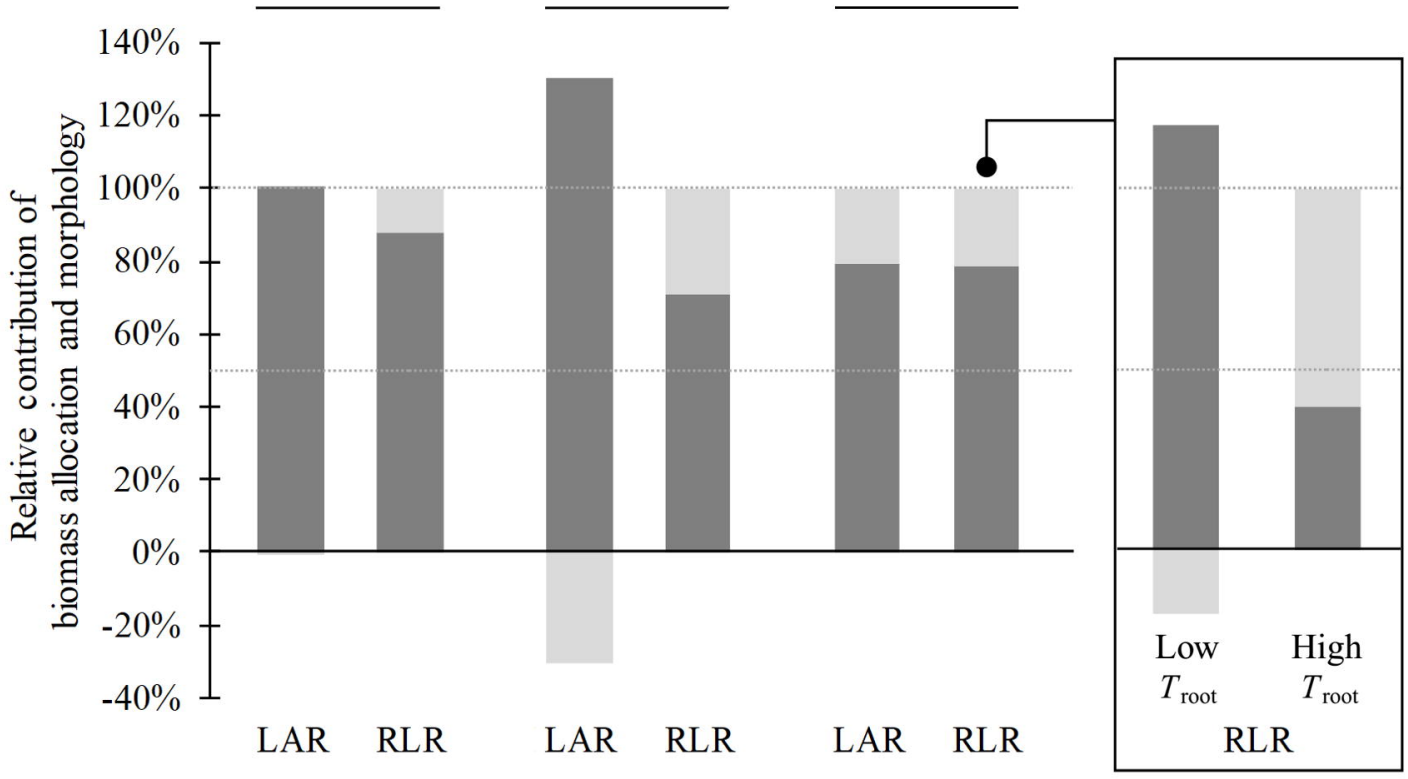

Biomass

allocation

Morphology 

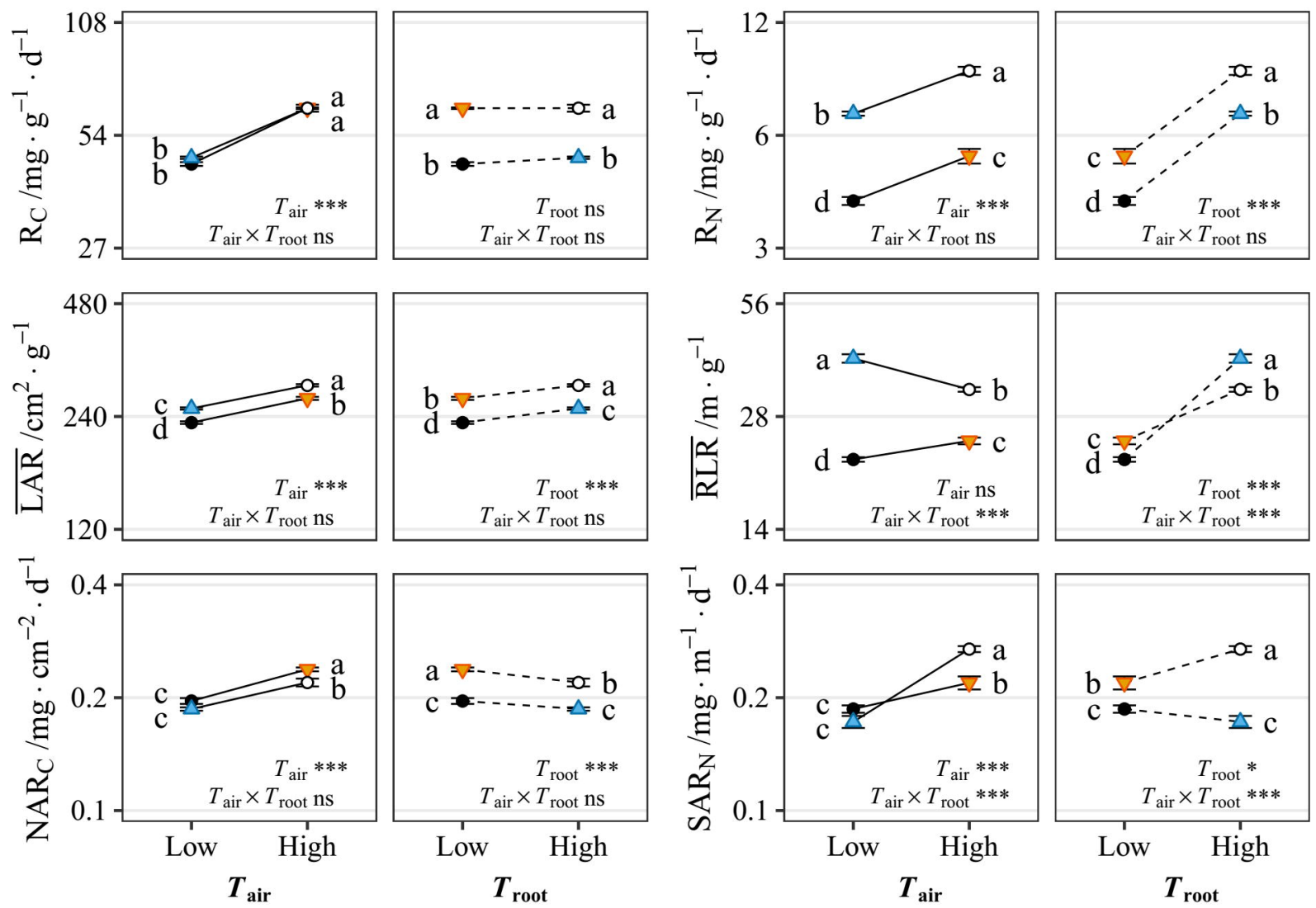

- $\mathrm{L} / \mathrm{L} \quad \Delta \mathrm{L} / \mathrm{H} \quad \nabla \mathrm{H} / \mathrm{L} \quad \circ \mathrm{H} / \mathrm{H}$ 


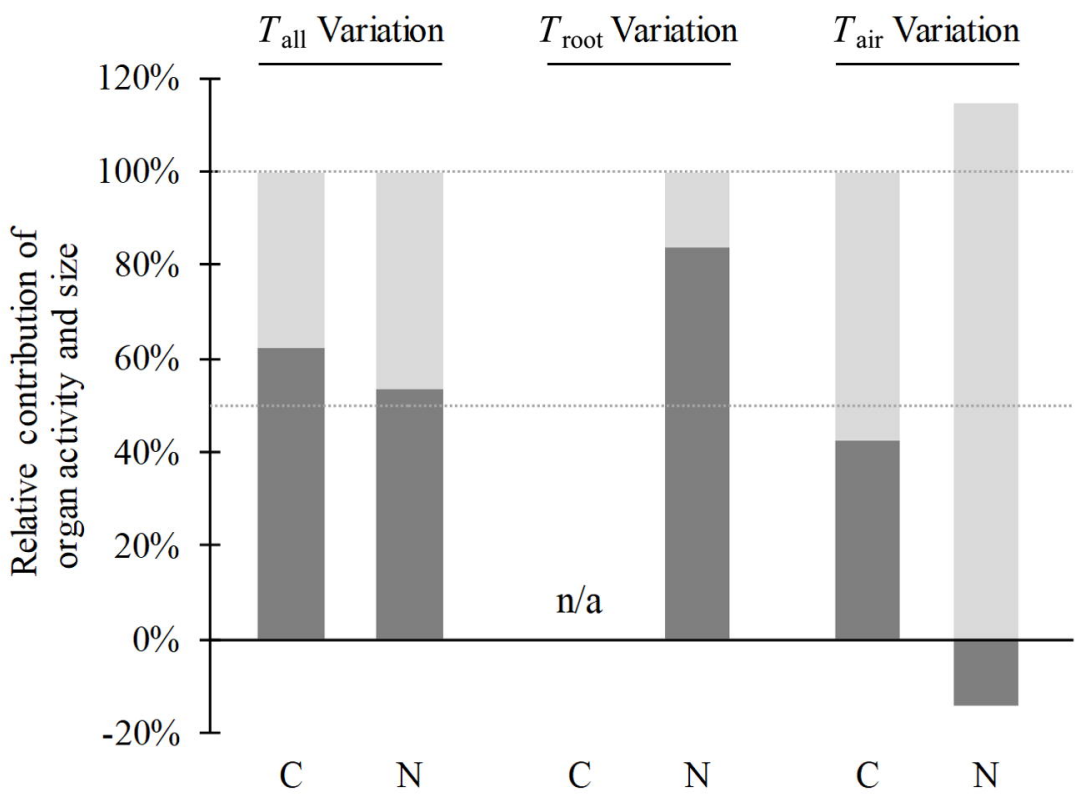

Organ activity

Organ size 
Relative

C allocation

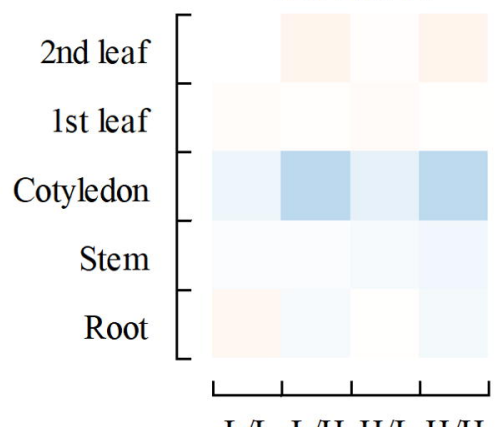

L/L L/H H/L H/H

C

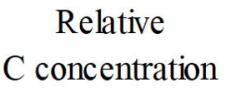

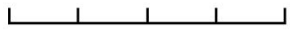

L/L L/H H/L H/H

E

Relative $\mathrm{C} / \mathrm{N}$ ratio

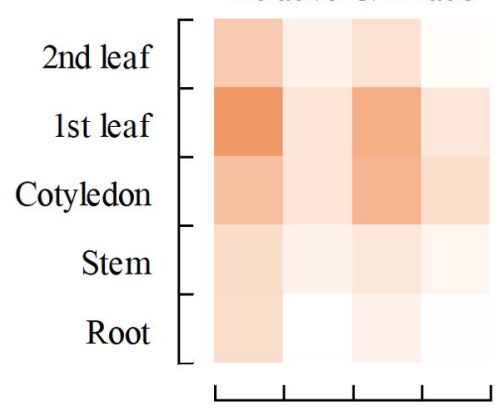

$\mathrm{L} / \mathrm{L} \mathrm{L} / \mathrm{H} \mathrm{H} / \mathrm{L} \mathrm{H} / \mathrm{H}$
Relative

$\mathrm{N}$ allocation

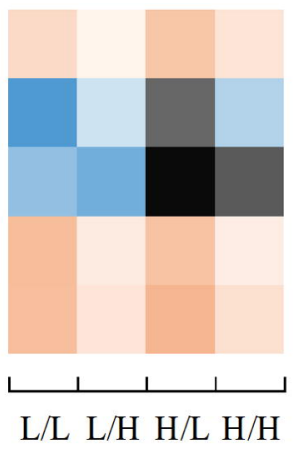

D

Relative

$\mathrm{N}$ concentration

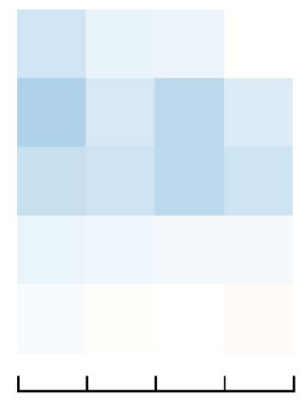

$\mathrm{L} / \mathrm{L} \mathrm{L/H} \mathrm{H/L} \mathrm{H/H}$

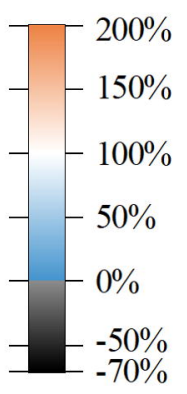



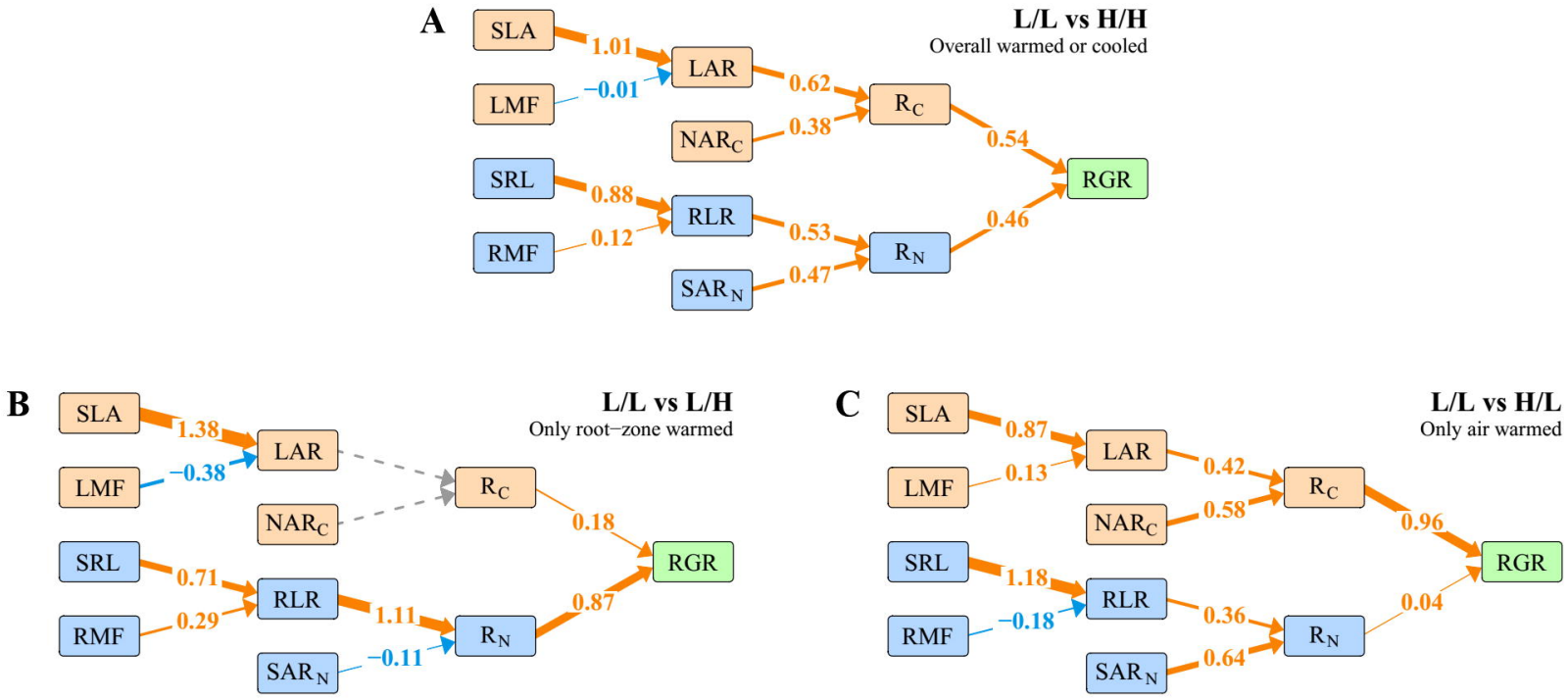

D

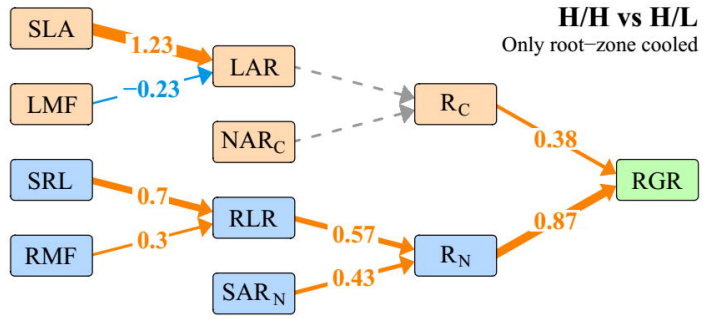

E

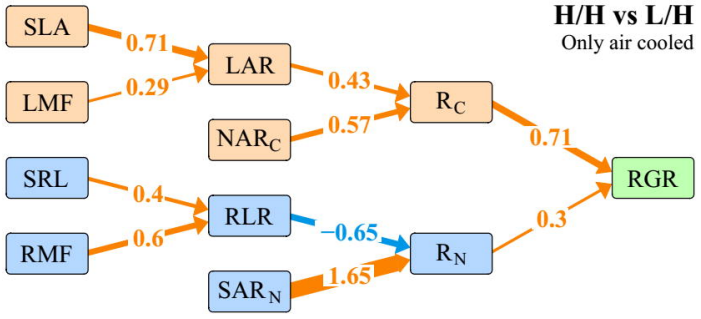

